\title{
S-Enantiomer of 19-Hydroxyeicosatetraenoic Acid Preferentially Protects Against Angiotensin II-Induced Cardiac Hypertrophy
}

\author{
Sherif M. Shoieb and Ayman O. S. El-Kadi \\ Faculty of Pharmacy and Pharmaceutical Sciences, University of Alberta, Edmonton, Alberta, Canada
}

Received April 16, 2018; accepted May 29, 2018

\begin{abstract}
We had recently demonstrated that the racemic mixture of 19-hydroxyeicosatetraenoic acid (19-HETE) protects against angiotensin II (Ang II)-induced cardiac hypertrophy. Therefore, the purpose of this study was to investigate whether the $R$ - or $S$ enantiomer of 19-HETE confers cardioprotection against Ang II-induced cellular hypertrophy in RL-14 and H9c2 cells. Both cell lines were treated with vehicle or $10 \mu \mathrm{M}$ Ang II in the absence and presence of $20 \mu \mathrm{M}$ 19(R)-HETE or 19(S)-HETE for 24 hours. Thereafter, the level of midchain HETEs was determined using liquid chromatography-mass spectrometry. Gene- and proteinexpression levels were measured using real-time polymerase chain reaction and Western blot analysis, respectively. The results showed that both $19(R)$-HETE and 19(S)-HETE significantly decreased the metabolite formation rate of midchain HETEs, namely 8-, 9-, 12-, and 15-HETE, compared with control group, whereas
\end{abstract}

the level of 5-HETE was selectively decreased by S-enantiomer. Moreover, both 19(R)-HETE and 19(S)-HETE significantly inhibited the catalytic activity of CYP1B1 and decreased the protein expression of 5- and 12-lipoxygenase (LOX) as well as cyclo-oxygenase-2 (COX-2). Notably, the decrease in 15-LOX protein expression was only mediated by 19(S)-HETE. Interestingly, both enantiomers protected against Ang II-induced cellular hypertrophy, as evidenced by a significant decrease in mRNA expression of $\beta / \alpha$-myosin heavy chain ratio, atrial natriuretic peptide, and interleukins 6 and 8. Our data demonstrated that S-enantiomer of 19-HETE preferentially protected against Ang II-induced cellular hypertrophy by decreasing the level of midchain HETEs, inhibiting catalytic activity of CYP1B1, decreasing protein expression of LOX and COX-2 enzymes, and decreasing mRNA expression of IL-6 and IL-8.

\section{Introduction}

Pathologic cardiac hypertrophy is considered a sign of poor prognosis in several heart diseases and it typically predisposes to most phenotypes of heart failure (Bernardo et al., 2010). The number of heart failure patients is continuously increasing in North America. The most up-to-date heart disease statistics showed that the number of the US heart failure patients ( $\geq 20$ years of age) has risen from 5.7 million (2009-2012) to 6.5 million (2011-2014) (Benjamin et al., 2017). In Canada, approximately 600,000 people are living with heart failure and it costs $\$ 2.8$ billion per year in direct costs (Heart and Stroke Foundation, 2016). In addition to heart failure, left ventricular hypertrophy is not only associated with myocardial infarction and arrhythmia but is also considered a solid predictor of future cardiovascular mortality (Brown et al., 2000; Elkhatali et al., 2015). Understanding conceptual aspects of the pathogenesis of cardiac hypertrophy is considered research into an important risk factor for heart failure and will enable the emergence of novel therapeutic targets.

One of the mechanisms involved in the regulation of cardiac hypertrophy is cytochrome P450 (P450) enzymes and their associated

This work was supported by a grant from the Canadian Institutes of Health Research [Grant 106665] to A.O.S.E.-K. S.M.S. is the recipient of Mike Wolowyk Graduate Scholarship.

https://doi.org/10.1124/dmd.118.082073. arachidonic acid (AA) metabolites (Roman, 2002). For years, AA was thought to be solely metabolized by cyclo-oxygenase (COX) and lipoxygenase (LOX) enzymes via conversion of AA into prostaglandins and leukotrienes (LTs), respectively (Chandrasekharan et al., 2016). In the heart, discovery of a novel branch of AA metabolism through P450 enzymes led to special focus on the role of their biologically active metabolites in multiple heart diseases (Westphal et al., 2015).

Cardiac P450 enzymes metabolize AA into three different metabolic pathways (Fig. 1), allylic oxidation to produce midchain hydroxyeicosatetraenoic acids (HETEs), namely 5-, 8-, 9-, 11-, 12-, and 15-HETE, which are known to be cardiotoxic metabolites, and olefinic epoxidation to form epoxyeicosatrienoic acids (EETs) exemplified as 5,6-, 8,9-, 11,12-, and 14,15-EET (Dhanasekaran et al., 2006; Elkhatali et al., 2017). The last pathway is terminal/subterminal hydroxylation producing terminal 20-HETE and subterminal 19-, 18-, 17-, and 16-HETE (Elshenawy et al., 2013).

Among subterminal HETEs, 19-hydroxyeicosatetraenoic acid (19-HETE) attracted the highest consideration as it represents the major cardiac subterminal HETE (El-Sherbeni and El-Kadi, 2014). 19-HETE acts as an endogenous antagonist of 20-HETE and inhibits its mediated vasoconstrictor effects (Elshenawy et al., 2017). Additionally, acute coronary syndrome patients with higher plasma levels of 19-HETE have significantly better prognosis than those who have lower plasma levels ( $\mathrm{Zu}$ et al., 2016). In a pressure overload-induced cardiac hypertrophy model, there was a significant decrease of the level of 19-HETE in

ABBREVIATIONS: AA, arachidonic acid; Ang II, angiotensin II; ANOVA, one-way analysis of variance; ANP, atrial natriuretic peptide; COX-2, cyclooxygenase-2; DMEM/F-12, Dulbecco's modified Eagle's medium/F-12; DMSO, dimethyl sulfoxide; EETs, epoxyeicosatrienoic acids; 19-HETE, 19hydroxyeicosatetraenoic acid; IL, interleukin; LOX, lipoxygenase; MROD, methoxyresorufin O-deethylase; $\alpha$-MHC, $\alpha$-myosin heavy chain; $\beta$-MHC, $\beta$-myosin heavy chain; MTT, 3-(4,5-dimethylthiazol-2-yl)-2,5-diphenyltetrazolium bromide; P450, cytochrome P450; SFM, serum-free medium. 


\section{Subterminal/terminal HETEs (16-, 17-, 18-, 19- and 20-HETE)}

\author{
Mid-chain HETEs \\ (5-, 8-, 9-, 11-, 12- and 15-HETE)
}
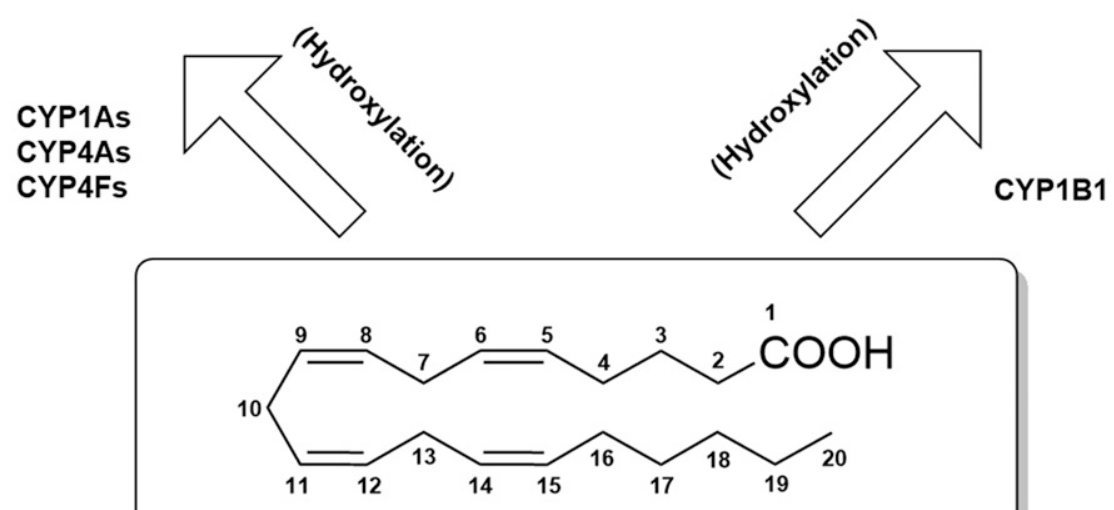

Arachidonic acid

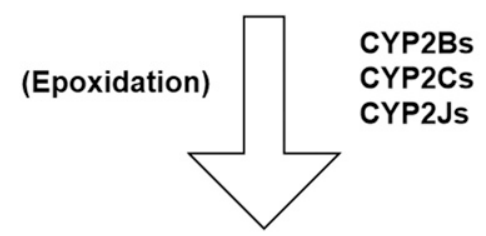

\section{EETs}

(5,6-, 8,9-, 11,12- and 14,15-EET)

Fig. 1. Cytochrome P450-mediated arachidonic acid metabolism. Arachidonic acid is metabolized by different P450 families into midchain HETEs (5-, 8-, 9-, 11-, 12-, and 15-HETE), subterminal/terminal HETEs (16-, 17-, 18-, 19-, and 20-HETE), and EETs (5,6-, 8,9-, 11,12-, and 14,15-EET).

hypertrophied hearts compared with control group (El-Sherbeni and El-Kadi, 2014). Furthermore, racemic mixture of ( \pm )19-HETE provides cardioprotection against angiotensin II (Ang II)-induced cardiac hypertrophy (Elkhatali et al., 2015).

19-HETE has $R$ - and $S$-enantiomers and they showed different activities in organs other than the heart. For instance, 19(S)-HETE directly stimulates the activity of $\mathrm{Na}+\mathrm{K}+$-ATPase renal proximal tubules leading to stimulation of proximal tubule transport, whereas 19(R)-HETE abolished 20-HETE-mediated inhibition of vasodilatory nitric oxide formation in renal arteries (Cheng et al., 2008). The aims of this study were to investigate the effects of 19(R)-HETE and 19(S)-HETE on cardiac P450 enzymes as well as their associated AA metabolites, elucidate the pathway involved, and examine whether both enantiomers have a cardioprotective effect in an in vitro model of cellular hypertrophy.

\section{Materials and Methods}

Materials. 19(R)- and 19(S)-HETEs, 15-HETE-D8 and 14, and 15-EET-D11 were purchased from Cayman Chemical (Ann Arbor, MI). Dulbecco's modified Eagle's medium/F-12 (DMEM/F-12) and DMEM were Gibco brand (Thermo Fisher Scientific, Grand Island, NY). TRIzol reagent was Invitrogen brand (Thermo Fisher Scientific, Carlsbad, CA). High Capacity cDNA Reverse Transcription Kit and SYBR Green PCR Master Mix were purchased from Applied Biosystems (Foster City, CA). Real-time polymerase chain reaction (PCR) primers were formulated by Integrated DNA Technologies (Coralville, IA). Immun-Blot PVDF Membrane was purchased from Bio-Rad Laboratories (Hercules, CA). GAPDH mouse monoclonal, 5-lipoxygenase (LOX) mouse monoclonal, 12-LOX rabbit polyclonal, 15-LOX mouse monoclonal, and cyclooxygenase-2 (COX-2) mouse monoclonal primary antibodies were purchased from Santa Cruz Biotechnology (Dallas, TX), and CYP1B1, CYP2B6, CYP2C8, and CYP4F2 rabbit polyclonal primary antibodies and CYP2J2 mouse monoclonal primary antibody were purchased from Abcam (Cambridge, UK). CYP4F11 mouse monoclonal primary antibodies were purchased from MilliporeSigma (St. Louis, MO). Chemiluminescence Western blotting detection reagents were obtained from GE Healthcare Life Sciences (Pittsburgh, PA). All other chemicals used were obtained from Fisher Scientific Co. (Toronto, ON).

Cell Culture. Rat cardiomyoblast (H9c2) cell line and human cardiomyocyte (RL-14) cells were obtained from American Type Culture Collection (Manassas, VA). $\mathrm{H} 9 \mathrm{c} 2$ cells were maintained in DMEM containing $10 \%$ heat-inactivated fetal bovine serum, and $1 \%$ penicillin-streptomycin. RL-14 cells were maintained in DMEM/F-12, with phenol red supplemented with $12.5 \%$ fetal bovine serum,

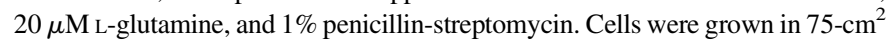
cell culture flasks at $37^{\circ} \mathrm{C}$ in a $5 \% \mathrm{CO}_{2}$ humidified environment.

Chemical Treatments. Cells were treated with vehicle [serum-free DMEM/F12 containing $0.1 \%$ dimethyl sulfoxide (DMSO) for RL-14 cells and serum-free DMEM containing 0.1\% DMSO for H9c2 cells] or $20 \mu \mathrm{M}$ 19(R)-HETE or 19(S)-HETE in serum-free medium (SFM) for the time indicated for each experiment as described in the figure legends. 19(R)-HETE or 19(S)-HETE was supplied as a stock solution in DMSO and maintained in DMSO at $-20^{\circ} \mathrm{C}$ until use. The treatment of cells was carried out in the corresponding culture media in 12-well cell culture plates for RNA assay and sixwell cell culture plates for protein and determination of AA metabolites assays. To investigate the effect of 19(R)-HETE or 19(S)-HETE on cardiac hypertrophic and inflammatory markers, cells were treated with $10 \mu \mathrm{M}$ Ang II in the absence and presence of $20 \mu \mathrm{M} \mathrm{19}(R)$-HETE or 19(S)-HETE for 24 hours as described in the figure legends. Ang II stock solution was prepared in saline and maintained at $-20^{\circ} \mathrm{C}$ until use. Diluted solutions of Ang II, 19(R)-HETE, or 19(S)-HETE were freshly prepared in SFM before each experiment. In all experiments, the DMSO concentration did not exceed $0.05 \%(\mathrm{v} / \mathrm{v})$.

Cell Viability Analysis. The viability of $\mathrm{H} 9 \mathrm{c} 2$ and RL-14 cells was measured by the MTT assay. The assay depends on the ability of viable cells to reduce tetrazolium dye MTT [3-(4,5-dimethylthiazol-2-yl)-2,5-diphenyltetrazolium 
TABLE 1

Primer sequences used for real-time PCR reactions

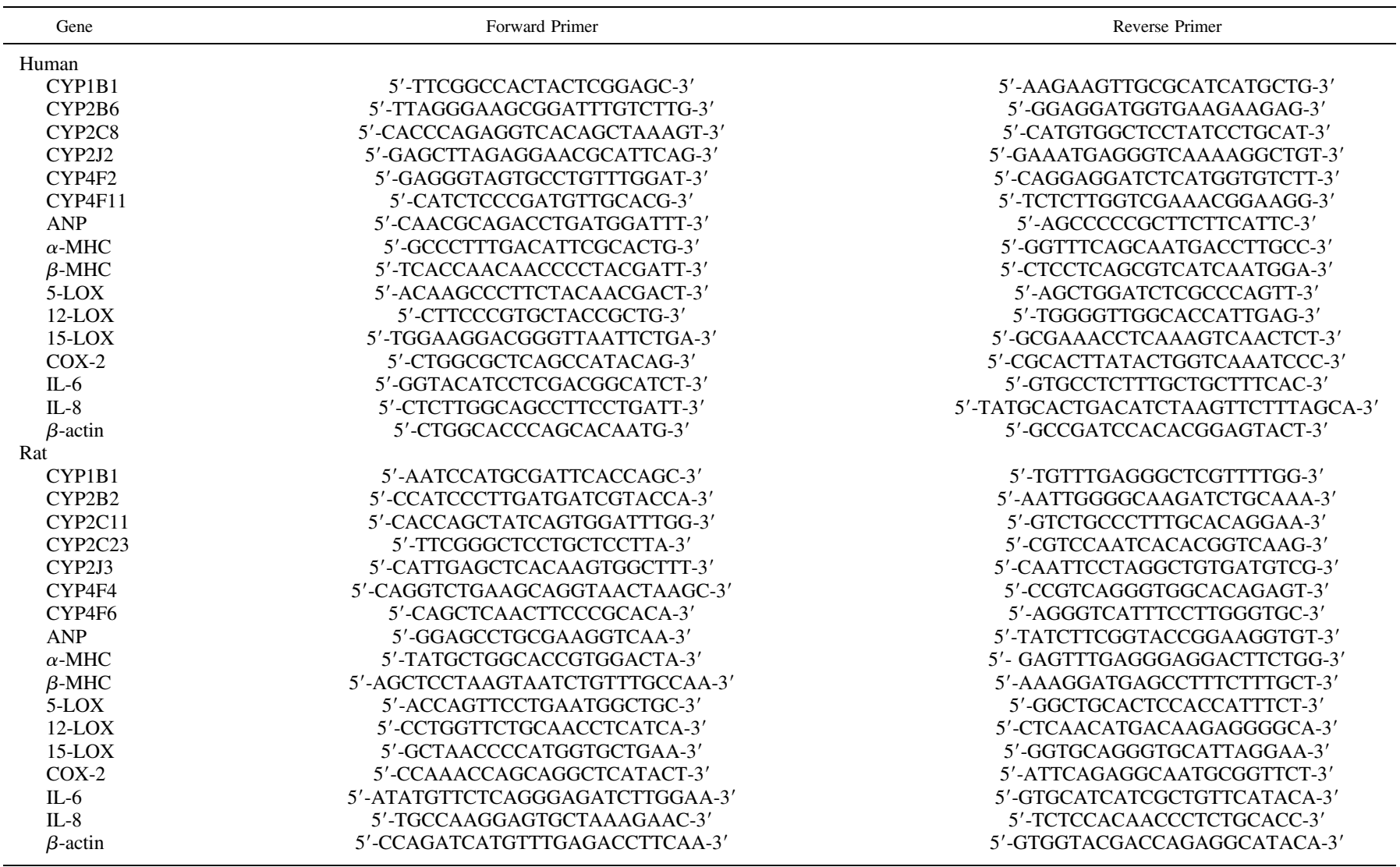

bromide] to its insoluble colored formazan crystals. In brief, cells were seeded in 96-well plates, treated as indicated, incubated for 24 hours at $37^{\circ} \mathrm{C}$ in a $5 \% \mathrm{CO}_{2}$ humidified incubator, incubated with $20 \mu 1 /$ well of MTT $(1.2 \mathrm{mM})$ dissolved in phosphate-buffered saline ( $\mathrm{pH} 7.4$ ) for 3 hours at $37^{\circ} \mathrm{C}$, and then $150 \mu \mathrm{l} /$ well of isopropyl alcohol to dissolve the formazan for 10 minutes at room temperature. The optical density was assessed at a wavelength of $550 \mathrm{~nm}$ using the Bio-Tek Synergy H1 Hybrid Multi-Mode microplate readers (Bio-Tek Instruments, Winooski, VT). The cell viability was presented as a percentage of the control mean absorbance value.

Metabolism of AA by H9c2 and RL-14 Cells. To investigate the effect of both enantiomers of 19-HETE on the AA metabolites, H9c2 and RL-14 cells were treated with vehicle or $20 \mu \mathrm{M}$ 19(R)-HETE or 19(S)-HETE in SFM for 24 hours and then the cells were incubated with $50 \mu \mathrm{M}$ AA for 3 hours. Extraction of AA metabolites was performed using ethyl acetate and dried using a speed vacuum (Savant Instruments, Inc., Farmingdale, NY). The resultant extracted AA and its metabolites were analyzed using liquid chromatography-electrospray ionization mass spectrometry (LC-ESI-MS) (Waters Micromass ZQ 4000 spectrometer; Waters Corporation, Milford, MA) method.

Apparatus and Chromatographic Conditions. The analysis of AA metabolites was performed using LC-ESI-MS as previously described (Elkhatali et al., 2017). In brief, the mode of the mass spectrometer was negative ionization mode with single-ion monitoring: $\mathrm{m} / \mathrm{z}=319$ for AA metabolites and $m / z=327$ and 330 for internal standards, 15-HETE-D8 and 14,15-EET-D11, respectively. The nebulizer gas was supplied from an in-house nitrogen source with high purity. The source was set to temperature of $150^{\circ} \mathrm{C}$, and voltage of the capillary and cone were $3.51 \mathrm{kV}$ and $25 \mathrm{~V}$, respectively. A gradient separation was performed on a reverse-phase $\mathrm{C} 18$ column (Alltima HP, $150 \times 2.1 \mathrm{~mm}$ ) at $35^{\circ} \mathrm{C}$. The mobile phase (A) was composed of water with $0.01 \%$ formic acid and $0.005 \%$ triethylamine (v/v), whereas mobile phase (B) consisted of $8 \%$ methanol, $8 \%$ isopropanol, and $84 \%$ acetonitrile with $0.01 \%$ formic acid, and $0.005 \%$ triethylamine $(\mathrm{v} / \mathrm{v})$. Samples were subjected to linear gradient elution at a flow rate of $200 \mu \mathrm{l} / \mathrm{min}$, as follows: $60 \%-48 \%$ in 4 minutes, held isocratically at $48 \%$ for 24 minutes, $48 \%-35 \%$ in 11 minutes, $35 \%-0 \%$ in 11 minutes, and finally held isocratically at $0 \%$ for 7 minutes of mobile phase $\mathrm{A}$.

RNA Extraction and cDNA Synthesis. RL-14 and H9c2 cells were seeded in 12-well plates and incubated with the test compounds for 24 hours. Afterward, cells were collected and total RNA was isolated using TRIzol reagent (Invitrogen) according to the manufacturer's instructions, and quantified by measuring the absorbance at $260 \mathrm{~nm}$ as the purity was determined by measuring the $260 / 280$ ratio $(>1.8)$. Thereafter, first-strand cDNA synthesis was carried out using the High-Capacity cDNA Reverse Transcription Kit (Applied Biosystems) according to the manufacturer's instructions. Briefly, $1.5 \mu \mathrm{g}$ of total RNA from each sample was added to a mix of $2.0 \mu \mathrm{l}$ of $10 \times$ Reverse Transcriptase buffer, Thermo Fisher Scientific RT buffer, $0.8 \mu 1$ of $25 \times$ dNTP mix $(100 \mathrm{mM}), 2.0 \mu 1$ of $10 \times$ reverse transcriptase random primers, $1.0 \mu \mathrm{l}$ of MultiScribe reverse transcriptase, and $4.2 \mu \mathrm{l}$ of nuclease-free water. The final reaction mixture was kept at $25^{\circ} \mathrm{C}$ for 10 minutes, heated to $37^{\circ} \mathrm{C}$ for 120 minutes, heated for $85^{\circ} \mathrm{C}$ for 5 minutes, and finally cooled to $4^{\circ} \mathrm{C}$.

Real-Time PCR for Quantification of mRNA Expression. Real-time PCR was used to quantitatively analyze specific mRNA expression of different targets by subjecting the resultant cDNA to PCR amplification using 96-well optical reaction plates in the ABI Prism 7500 System (Applied Biosystems). The 25- $\mu$ l reaction mixture contained $0.1 \mu \mathrm{l}$ of $10 \mu \mathrm{M}$ forward primer and $0.1 \mu \mathrm{l}$ of $10 \mu \mathrm{M}$ reverse primers (40 $\mathrm{nM}$ final concentration of each primer), $12.5 \mu \mathrm{l}$ of SYBR Green Universal Master mix, $11.05 \mu \mathrm{l}$ of nuclease-free water, and $1.25 \mu \mathrm{l}$ of cDNA sample. Human primer sequences for CYP1B1, CYP2B6, CYP2C8, CYP2J2, CYP4F2, CYP4F11, atrial natriuretic peptide (ANP), $\alpha$-myosin heavy chain $(\alpha$-MHC), $\beta$-myosin heavy chain ( $\beta$-MHC), 5-LOX, 12-LOX, 15-LOX, COX-2, IL-6, IL-8, and $\beta$-actin as well as rat primer sequences for CYP1B1, CYP2B2, CYP2C11, CYP2C23, CYP2J3, CYP4F4, CYP4F6, ANP, $\alpha$-MHC, $\beta$-MHC, 5-LOX, 12-LOX, 15-LOX, COX-2, IL-6, IL-8, and $\beta$-actin are listed in Table 1. These primers were purchased from Integrated DNA Technologies 
(Coralville, IA). Analysis of the real-time PCR data was performed using the relative gene expression (i.e., $\Delta \Delta \mathrm{CT}$ ) method. In short, the fold change in the level of target genes between treated and untreated cells, corrected for the level of $\beta$-actin, was determined using the following equation: fold change $=2^{-\Delta(\Delta \mathrm{Ct})}$, where $\Delta \mathrm{Ct}=\mathrm{Ct}$ (target) $-\mathrm{Ct}(\beta$-actin $)$ and $\Delta(\Delta \mathrm{Ct})=\Delta \mathrm{Ct}($ treated $)-\Delta \mathrm{Ct}$ (untreated). The thermal cycle parameters were as follow: initiation of the reaction at $95^{\circ} \mathrm{C}$ for 10 minutes and 40 cycles of denaturation $\left(95^{\circ} \mathrm{C}, 15\right.$ seconds) and combined annealing/extension $\left(60^{\circ} \mathrm{C}, 60\right.$ seconds).

Protein Extraction. Cells were grown in six-well plates and incubated with the test compounds for 24 hours. Afterward, lysis buffer containing $50 \mathrm{mM}$ HEPES, $0.5 \mathrm{M}$ sodium chloride, $1.5 \mathrm{mM}$ magnesium chloride, $1 \mathrm{mM}$ EDTA, $10 \%$ (v/v) glycerol, $1 \%$ Triton $\mathrm{X}-100$, and $5 \mu \mathrm{l} / \mathrm{ml}$ of protease inhibitor cocktail was used to collect the cells. The cell homogenates were prepared by incubating the cell lysates on ice for 1 hour, with sporadic vortex every 10 minutes, followed by centrifugation at $12,000 \mathrm{~g}$ for 10 minutes at $4^{\circ} \mathrm{C}$. Supernatant of total cellular lysate was collected and stored at $-80^{\circ} \mathrm{C}$. Afterward, the Lowry method was used to determine concentration of protein by using bovine serum albumin as a standard (Lowry et al., 1951).

Western Blot Analysis. Western blot analysis was carried out according to a previously described assay (Mosli et al., 2015). In brief, total cell lysates $(50 \mu \mathrm{g}$ ) were separated by $10 \%$ SDS-PAGE and then samples underwent electrophoresis at $120 \mathrm{~V}$ for 2 hours and separated proteins were transferred onto Immun-Blot PVDF Membrane. Then, protein membranes were blocked overnight at $4^{\circ} \mathrm{C}$ using blocking solution containing $0.15 \mathrm{M}$ sodium chloride, $3 \mathrm{mM}$ potassium chloride, $25 \mathrm{mM}$ Tris-base, $5 \%$ skim milk, $2 \%$ bovine serum albumin, and $0.5 \%$ Tween 20 . After blocking, the blots were subjected to washing three times for 30 minutes with Tris-buffered saline (TBS)-Tween-20. The blots were then incubated for 2 hours at $4{ }^{\circ} \mathrm{C}$ with primary antibodies in TBS solution $[0.05 \%$ (v/v) Tween-20, $0.02 \%$ sodium azide]. Incubation with a peroxidase-conjugated $\mathrm{IgG}$ secondary antibodies in blocking solution was performed for 1 hour at room temperature. Visualization of the bands was carried out using the enhanced chemiluminescence method according to the manufacturer's instructions (GE Healthcare Life Sciences). ImageJ software (National Institutes of Health, Bethesda, MD; http:// rsb.info.nih.gov/ij) was used to quantify the intensity of the protein bands in relation to the signals acquired from $(\beta$-actin or GAPDH) loading control. Data, given in the figures, are represented as relative protein intensity $(\%)+$ S.E.M., as compared with control group.

Assessment of CYP1B1 Enzymatic Activity. Enzymatic activity of CYP1B1 was determined by methoxyresorufin $O$-deethylase (MROD) assay, performed on intact living RL-14 and H9c2 cells (Maayah et al., 2017). Briefly, the cells were seeded in 24-well plates and test compounds and methoxyresorufin $(5 \mu \mathrm{M})$ in assay buffer $(0.05 \mathrm{M}$ Tris, $0.1 \mathrm{M} \mathrm{NaCl}, \mathrm{pH} 7.8)$ were added. Instantly, an initial fluorescence measurement $(t=0)$ at excitation/emission wavelengths $(535 / 585 \mathrm{~nm})$, respectively, was carried out. Fluorescence of the samples was recorded every 5-minute interval for 40 minutes using the Bio-Tek Synergy H1 Hybrid Multi-Mode microplate readers (Bio-Tek Instruments). The content of each sample of resorufin formed was assessed by comparison with a standard curve of known concentrations. The CYP1B1 enzymatic activity was normalized to protein content in the cells, which was assessed using a fluorescence-based protein assay (Lorenzen and Kennedy, 1993). The formation rate of resorufin was represented as picomoles per minute per milligram protein.

Statistical Analysis. All results are presented as the mean \pm SEM. Multiple group comparisons were carried out using one-way analysis of variance (ANOVA) followed by the Student-Newman-Keuls as a post-hoc test. Differences between means were considered significant at $P<0.05$. All analyses were performed using SigmaPlot for Windows (Systat Software, San Jose, CA).

\section{Results}

Effect of 19(R)-HETE and 19(S)-HETE on Cell Viability. To determine the maximum concentrations of both enantiomers of 19-HETE that do not possess a toxic effect on the cells, human RL-14 and rat H9c2 cells were treated for 24 hours with increasing concentrations of 19(R)-HETE or 19(S)-HETE ranging from 5 to $40 \mu \mathrm{M}$. Thereafter, cell viability was assessed using the MTT assay. Figure 2 shows that both enantiomers, over the concentration range used, did not significantly affect the cell viability of the two cell lines (cell viability was above 90\%).

\section{A}

RL-14 cells

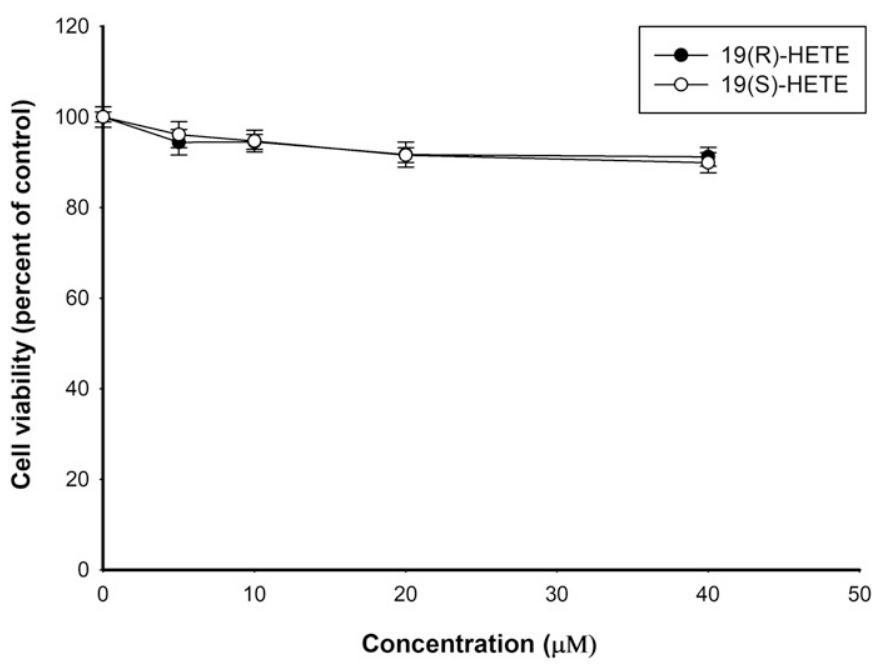

B H9c2 cells

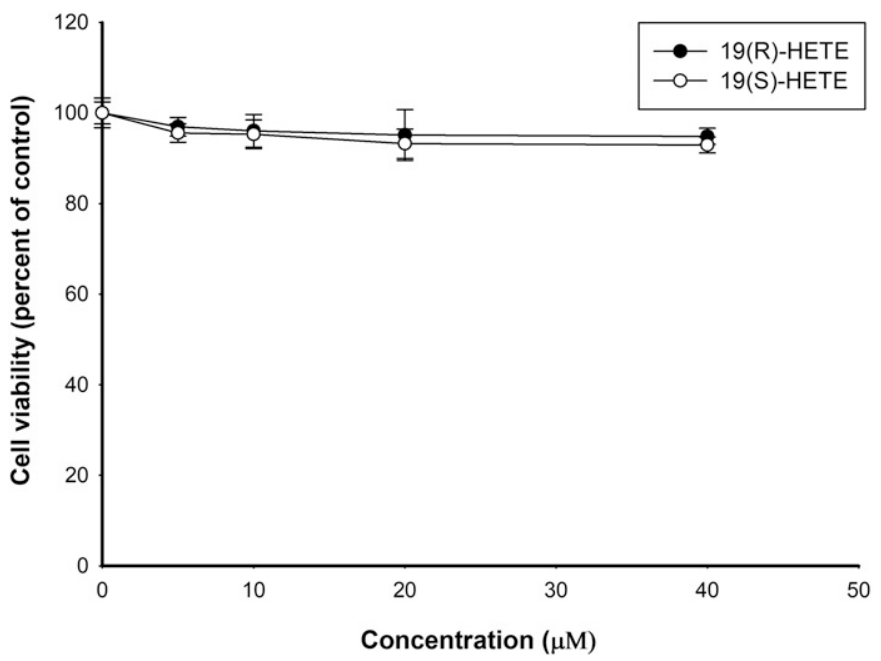

Fig. 2. Effect of 19(R)-HETE and 19(S)-HETE on cell viability in RL-14 and H9c2 cells. RL-14 (A) and H9c2 (B) cells were treated for 24 hours with 5-40 $\mu \mathrm{M} 19(R)$ HETE or 19(S)-HETE. Cell cytotoxicity was assessed using the MTT assay. Data are presented as the percentage of control (set at $100 \%) \pm$ S.E.M. $(n=8)$. Data were analyzed using one-way ANOVA followed by Student-Newman-Keuls as post-hoc test.

Consequently, $20 \mu \mathrm{M}$ was selected to perform all subsequent experiments in this study on the basis of these MTT assay results.

Effect of 19(R)-HETE and 19(S)-HETE on the Formation of Midchain HETEs. To investigate the effect of both enantiomers of 19-HETE on the formation of AA metabolites, RL-14 cells were treated for 24 hours with vehicle or $20 \mu \mathrm{M} 19(R)$-HETE or 19(S)-HETE. Thereafter, the cells were incubated with $50 \mu \mathrm{M}$ AA for 3 hours and AA metabolites (midchain HETEs, EETs, and subterminal/terminal HETEs) were analyzed using LC-ESI-MS. Figure 3A shows that treatment of RL-14 cells with 19(R)-HETE significantly decreased the level of 15-HETE, 11-HETE, 12-HETE, 8-HETE, and 9-HETE by approximately $21 \%, 28 \%, 25 \%, 22 \%$, and $25 \%$, respectively, compared with control group with no significant 
A

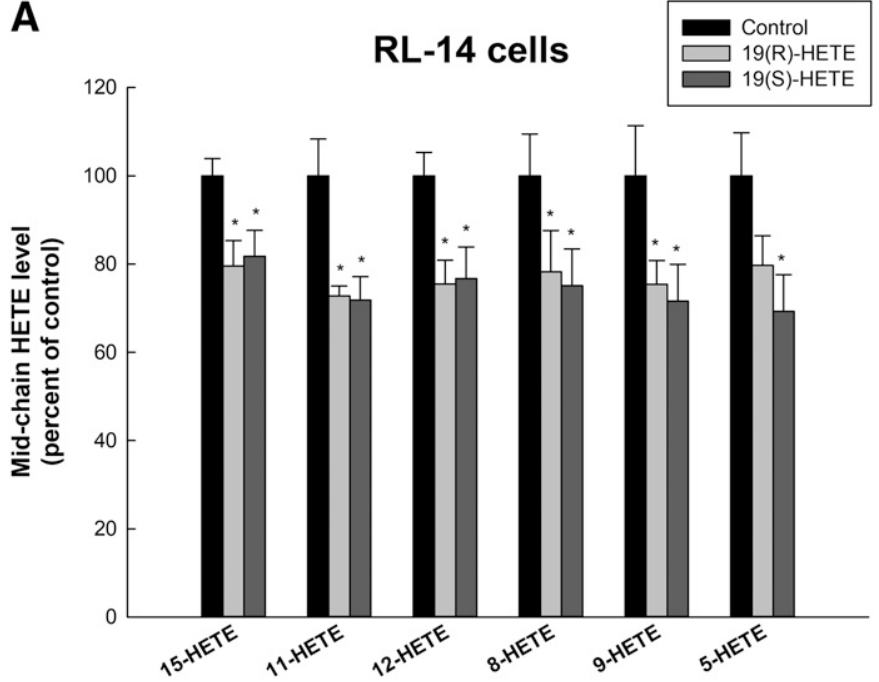

B

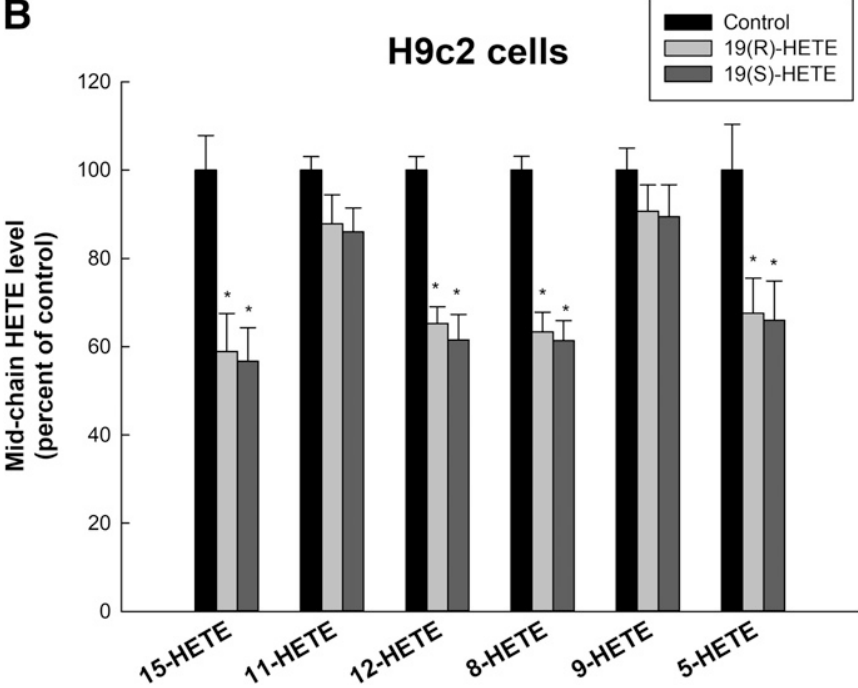

Fig. 3. Effect of 19(R)-HETE and 19(S)-HETE on midchain HETE level in RL-14 and $\mathrm{H} 9 \mathrm{c} 2$ cells. RL-14 (A) and H9c2 (B) cells were treated for 24 hours with $20 \mu \mathrm{M}$ 19(R)-HETE or 19(S)-HETE. 5-, 8-, 9-, 11-, 12-, and 15-HETE metabolites were measured using LC-ESI-MS. The results are presented as the mean and S.E.M. $(n=$ $6)$. Data were analyzed using one-way ANOVA followed by Student-NewmanKeuls as post-hoc test. $* P<0.05$ significantly different from control group.

effect on the level of 5-HETE. On the other hand, the $S$-enantiomer was able to significantly decrease the level of all midchain HETEs, namely 15-HETE, 11-HETE, 12-HETE, 8-HETE, 9-HETE, and 5-HETE, by approximately $19 \%, 29 \%, 24 \%, 25 \%, 29 \%$, and $31 \%$, respectively, compared with control. To confirm the results in another species, we used rat H9c2 cells. The results showed that both 19(R)-HETE and 19(S)-HETE significantly decreased the level of midchain HETEs, namely 15-HETE, 12-HETE, 8-HETE, and 5-HETE by approximately $42 \%, 35 \%, 37 \%, 33 \%$, and $44 \%, 39 \%, 39 \%, 35 \%$, respectively (Fig. 3B).

Effect of 19(R)-HETE and 19(S)-HETE on the Formation of EETs and Subterminal/Terminal HETEs. The decrease in the formation of midchain HETEs prompted us to examine the effect of both enantiomers of 19-HETE on other AA metabolites, such as EETs and subterminal/terminal HETEs. Our results showed that treatment of RL-14 cells with vehicle or $20 \mu \mathrm{M} 19(R)$-HETE or 19(S)-HETE for 24 hours did not significantly alter the formation rate of EETs (Fig. 4A),
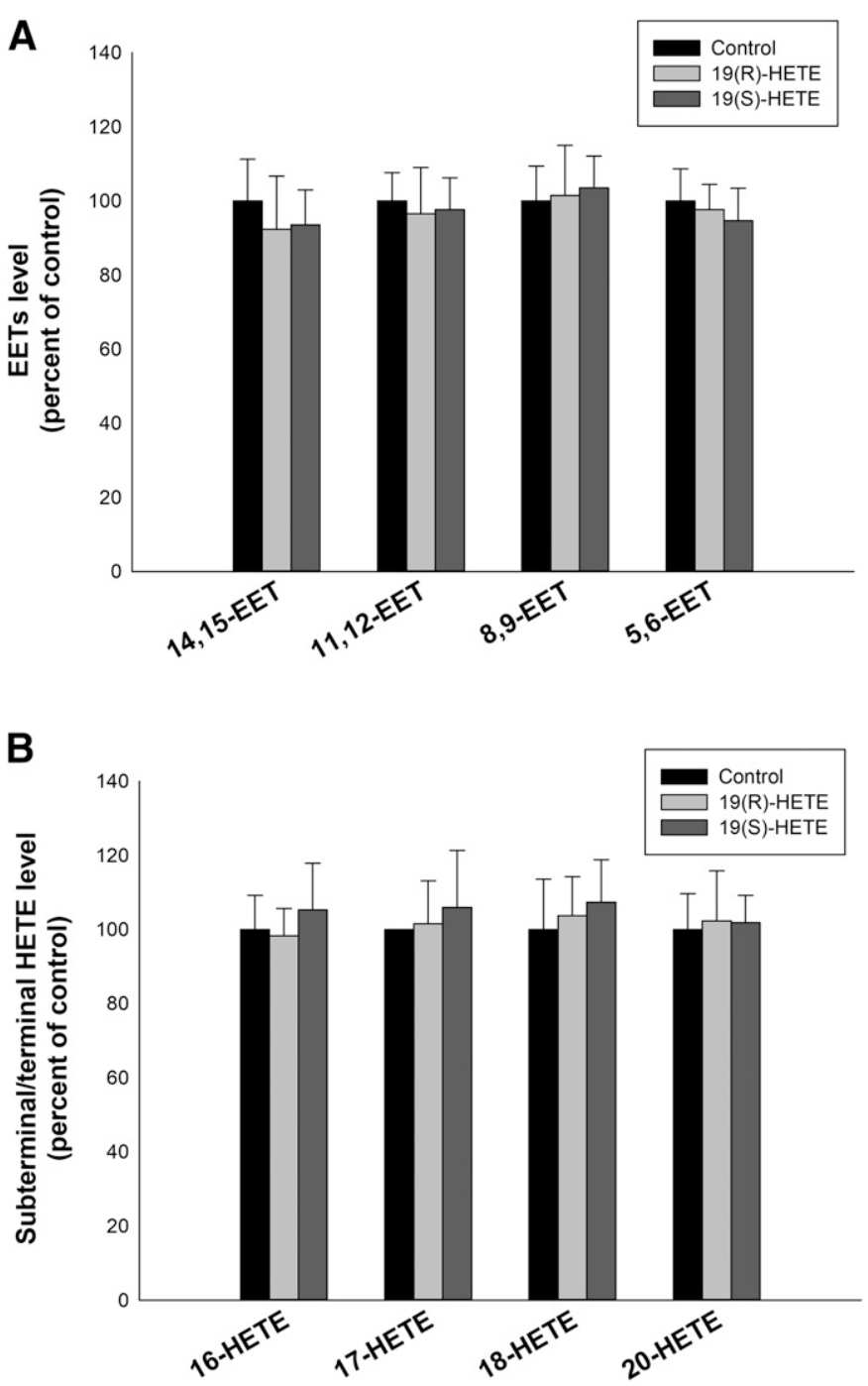

Fig. 4. Effect of 19(R)-HETE and 19(S)-HETE on EETs and subterminal/terminal HETEs levels in RL-14 cells. RL-14 cells were treated for 24 hours with $20 \mu \mathrm{M}$ 19(R)-HETE or 19(S)-HETE. (A) 5,6-, 8,9-, 11,12-, and 14,15-EET and (B) 20-, 18-, $17-$, and 16-HETE metabolites were measured using LC-ESI-MS. The results are presented as the mean and S.E.M. $(n=6)$. Data were analyzed using one-way ANOVA followed by Student-Newman-Keuls as post-hoc test.

namely 14,15-EET, 11,12-EET, 8,9-EET, and 5,6-EET or subterminal/terminal HETEs (Fig. 4B), specifically 16-HETE, 17-HETE, 18-HETE, and 20-HETE compared with control group.

Effect of 19(R)-HETE and 19(S)-HETE on the mRNA and Protein Expression of Cytochrome P450 Epoxygenases and Hydroxylases. To elucidate the mechanism by which both enantiomers of 19-HETE decrease the formation of midchain HETEs, the three pathways involved in midchain HETE formation were further investigated. The first pathway involves P450 enzymes such as epoxygenases, hydroxylases, and CYP1B1. The effect of 19(R)-HETE and 19(S)-HETE on P450 epoxygenases (CYP2B6, CYP2C8, and CYP2J2) and P450 hydroxylases (CYP4F2 and CYP4F11) was assessed (in RL-14 cells) by mRNA expression level using real-time PCR and by protein expression level using Western blot analysis. Regarding P450 epoxygenases, the results showed that both enantiomers of 19-HETE have no significant effect on CYP2B6, CYP2C8, or CYP2J2 on mRNA (Fig. 5A) or protein expression (Fig. 5B) level compared with control group. On the other hand, the $S$ enantiomer of 19-HETE significantly 
A
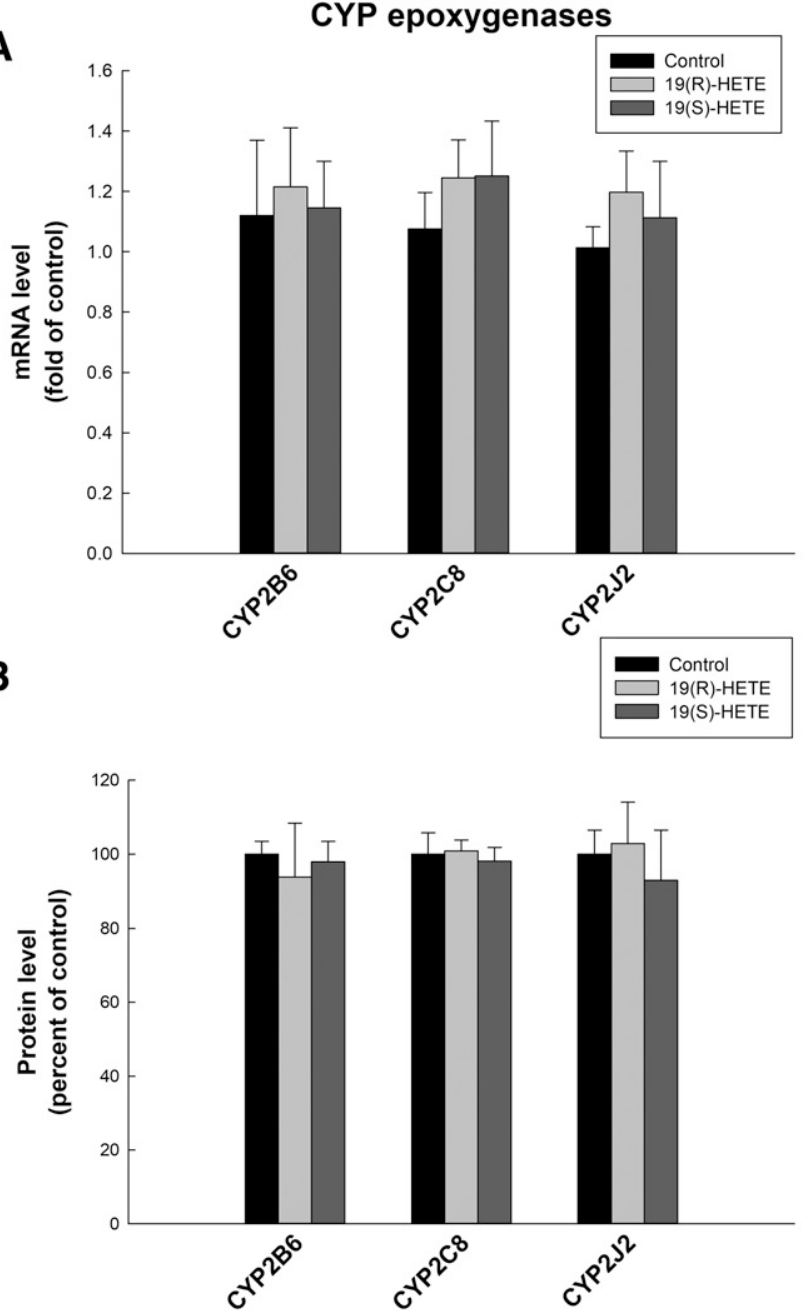

CYP2J2

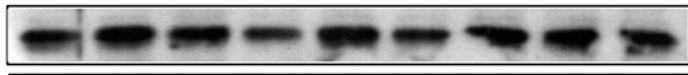

CYP2C8

CYP2B6

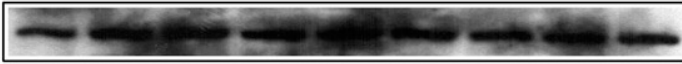

$\beta$-Actin
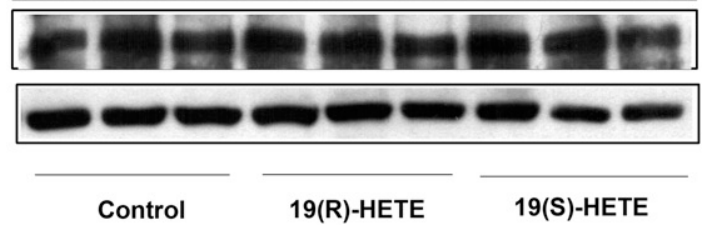

Fig. 5. Effect of 19(R)-HETE and 19(S)-HETE on mRNA and protein expression of CYP2B6, CYP2C8, and CYP2J2 in RL-14 cells. RL-14 cells were treated for 24 hours with $20 \mu \mathrm{M} 19(R)$-HETE or 19(S)-HETE. CYP2B6, CYP2C8, and CYP2J2 mRNA (A) and protein (B) expression levels were determined using realtime PCR and Western blot analysis, respectively. For real-time PCR, total RNA was isolated using TRIzol reagent, the mRNA level was quantified, and its level was normalized to $\beta$-actin housekeeping gene. For Western blot analysis, protein levels were detected using the enhanced chemiluminescence method. The intensity of the protein band was normalized to the signals obtained for $\beta$-actin protein and quantified using ImageJ. The results are presented as the mean and S.E.M. of at least three individual experiments. Data were analyzed using one-way ANOVA followed by Student-Newman-Keuls as post-hoc test.

increased CYP4F2 and CYP4F11 mRNA expression level by $81 \%$ and $82 \%$, respectively (Fig. 6A). In agreement with the mRNA expression results, Western blot analysis showed that the protein expression levels of CYP4F2 and CYP4F11 were also increased by 19(S)-HETE by $82.7 \%$ and $68.3 \%$, respectively (Fig. 6B).

\section{CYP hydroxylases}

A

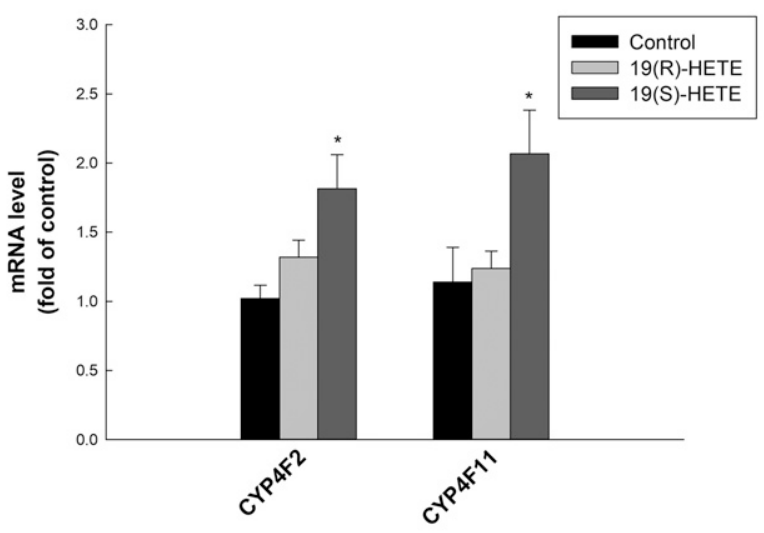

B

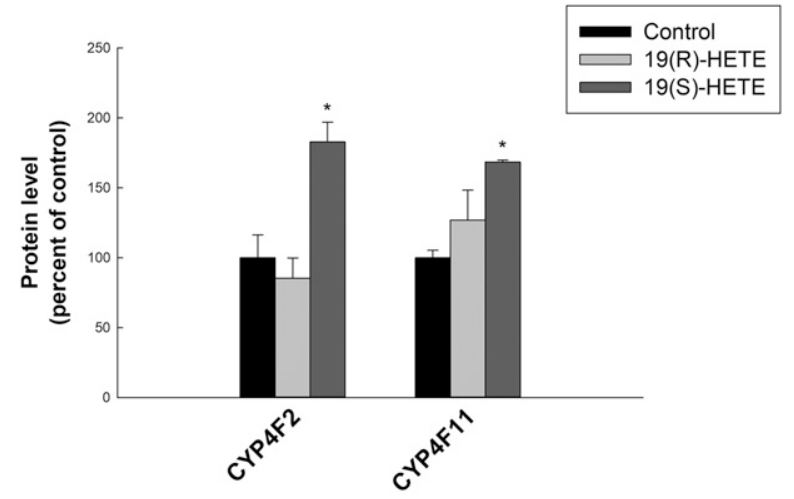

CYP4F11

CYP4F2

$\beta$-Actin

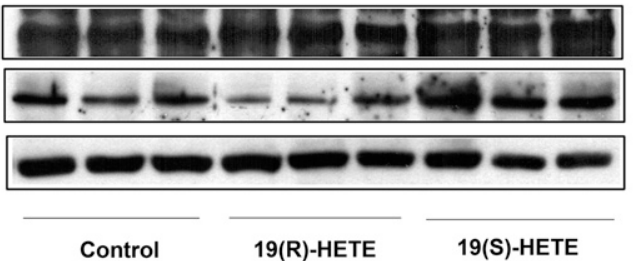

Fig. 6. Effect of 19(R)-HETE and 19(S)-HETE on mRNA and protein expression of CYP4F2 and CYP4F11 in RL-14 cells. RL-14 cells were treated for 24 hours with $20 \mu \mathrm{M} 19(R)$-HETE or 19(S)-HETE. CYP4F2 and CYP4F11 mRNA (A) and protein (B) expression levels were determined using real-time PCR and Western blot analysis, respectively. For real-time PCR, total RNA was isolated using TRIzol reagent, the mRNA level was quantified, and its level was normalized to $\beta$-actin housekeeping gene. For Western blot analysis, protein levels were detected using the enhanced chemiluminescence method. The intensity of the protein band was normalized to the signals obtained for $\beta$-actin protein and quantified using ImageJ. The results are presented as the mean and S.E.M. of at least three individual experiments. Data were analyzed using one-way ANOVA followed by StudentNewman-Keuls as post-hoc test. ${ }^{*} P<0.05$ significantly different from control group.

Effect of 19(R)-HETE and 19(S)-HETE on the mRNA, Protein Expression, and Enzymatic Activity of CYP1B1. The effect of both enantiomers of 19-HETE on CYP1B1 was determined at three levels: First was mRNA expression level, and the results showed that $R$ - and $S$-enantiomers of 19-HETE did not significantly affect CYP1B1 mRNA expression compared with control group in RL-14 and H9c2 cells (Fig. 7A). In agreement with the mRNA results, Western blot analysis showed that protein expression of CYP1B1 was not significantly altered by treatment with both enantiomers compared with control group in both cell lines, RL-14 and H9c2 cells (Fig. 7B). To examine the effect of both enantiomers on the functional catalytic activity of CYP1B1, MROD assay was carried out. Figure 7C shows that, in RL-14 cells, 19(R)-HETE, and 19(S)-HETE significantly decreased the formation of 

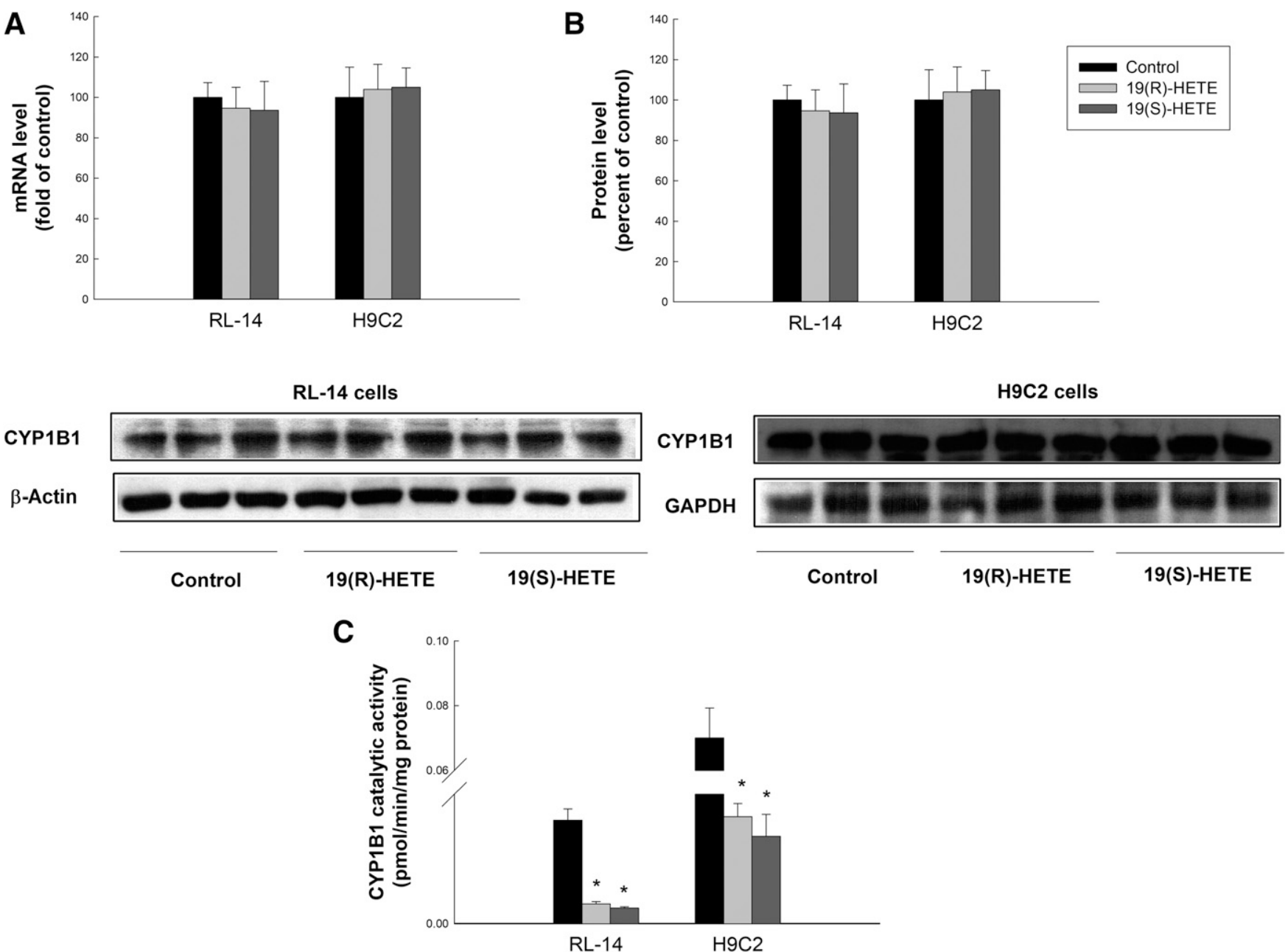

Fig. 7. Effect of 19(R)-HETE and 19(S)-HETE on mRNA expression, protein expression levels, as well as catalytic activity of CYP1B1 in RL-14 and H9c2 cells. RL-14 and H9c2 cells were treated for 24 hours with $20 \mu \mathrm{M}$ 19(R)-HETE or 19(S)-HETE. CYP1B1 mRNA expression (A), protein expression levels (B), and catalytic activity (C) were determined using real-time PCR, Western blot analysis, and MROD assay, respectively. For real-time PCR, total RNA was isolated using TRIzol reagent, the mRNA level was quantified, and its level was normalized to $\beta$-actin housekeeping gene. For Western blot analysis, protein levels were detected using the enhanced chemiluminescence method. The intensity of protein band was normalized to the signals obtained for $\beta$-actin or GAPDH protein and quantified using ImageJ. The results are presented as the mean and S.E.M. on the basis of at least three individual experiments. Data were analyzed using one-way ANOVA followed by Student-Newman-Keuls as post-hoc test. $* P<0.05$ significantly different from control group.

resorufin by approximately $80 \%$ and $85 \%$, respectively, compared with control group. To confirm this result in a different cell line, H9c2 cells were used. The results showed that both $R$ and $S$ enantiomers significantly decreased the resorufin formation by approximately $82 \%$ and $85 \%$, respectively (Fig. 7C).

Effect of 19(R)-HETE and 19(S)-HETE on 5-LOX, 12-LOX, 15-LOX, and COX2 Protein Expression Levels. To investigate the other two pathways involved in the formation of midchain HETEs, protein expression levels of 5-LOX, 12-LOX, 15-LOX, and COX-2 were assessed using Western blot analysis. For this purpose, RL-14 cells were treated with both enantiomers for 24 hours and the results showed that both $R$ and $S$ enantiomers of 19-HETE were able to significantly decrease the protein expression levels of 5-LOX, 12-LOX (Fig. 8A), and COX-2 (Fig. 8B) by approximately $29 \%$ and $44 \%, 59 \%$ and $50 \%$, and $54 \%$ and $74 \%$, respectively, compared with control group. It is worth noting that 15 -LOX protein expression level was selectively decreased by the $S$ enantiomer of 19-HETE by approximately $45 \%$, compared with control group (Fig. 8A). To further confirm the data obtained from RL-14 cells, rat cardiomyoblast H9c2 cells were treated with 19(R)-HETE and 19(S)-HETE for 24 hours. The results showed that both enantiomers significantly decreased protein expression levels of 5-LOX, 12-LOX, and 15-LOX by approximately $53 \%$ and $64 \%, 82 \%$ and $91 \%$, and $53 \%$ and $42 \%$, respectively, compared with control group (Fig. 8A). Furthermore, 19(R)-HETE and 19(S)-HETE significantly decreased COX-2 protein expression level by approximately $75 \%$ and $58 \%$, respectively, compared with control group (Fig. 8B).

Effect of 19(R)-HETE and 19(S)-HETE on Ang II-Induced Cellular Hypertrophy. To investigate the effect of 19(R)-HETE and 19(S)-HETE on the development of cellular hypertrophy, the cells were treated with Ang II in the absence and presence of both enantiomers of 19-HETE. The results showed that treatment of cells with $10 \mu \mathrm{M}$ Ang II for 24 hours caused cellular hypertrophy as evidenced by a significant increase in $\beta / \alpha$-MHC ratio and ANP by approximately $80 \%$ and $75 \%$, respectively in RL-14 cells, compared with control group (Fig. 9A). Of interest, both $R$ and $S$ enantiomers of 19-HETE significantly attenuated Ang II-mediated increase of $\beta / \alpha$-MHC ratio and ANP to nearly control level. Furthermore, treatment of $\mathrm{H} 9 \mathrm{c} 2$ cells with $10 \mu \mathrm{M}$ Ang II for 24 hours significantly increased $\beta / \alpha$-MHC ratio and ANP mRNA expression by approximately $97 \%$ and $100 \%$, respectively, compared with control group. On the other hand, 19(R)-HETE and 19(S)-HETE 
A
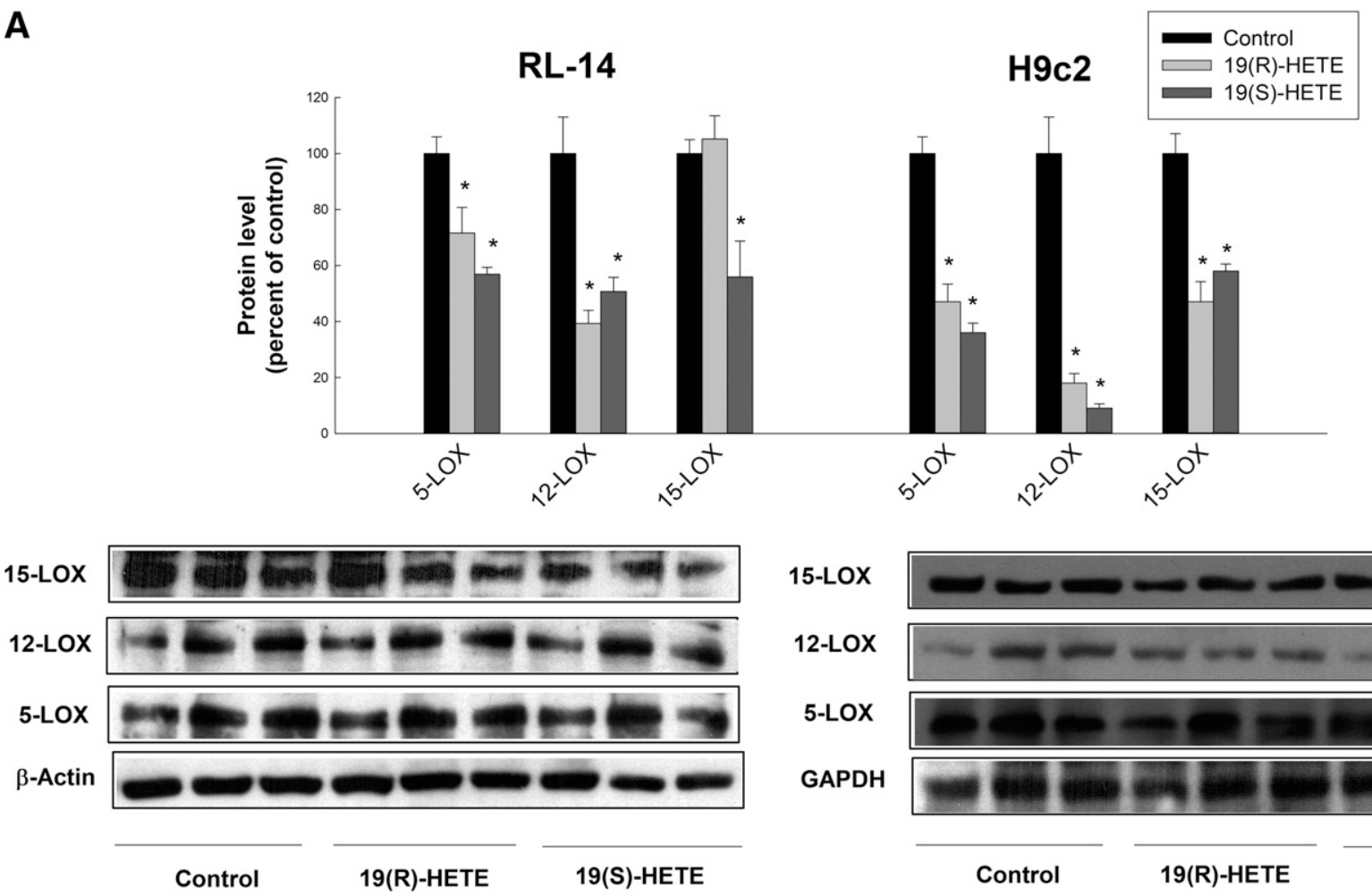

15-LOX

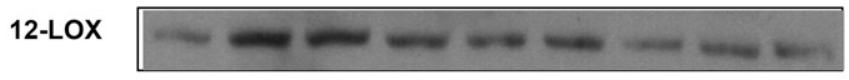

5-LOX

GAPDH

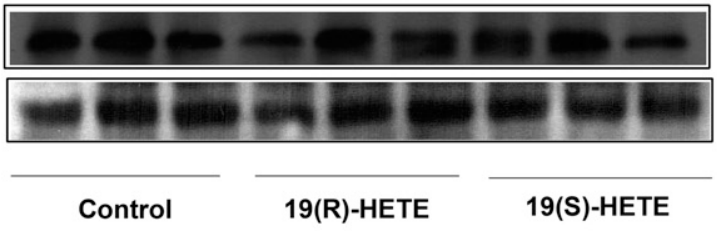

B



coX-2

$\beta$-Actin

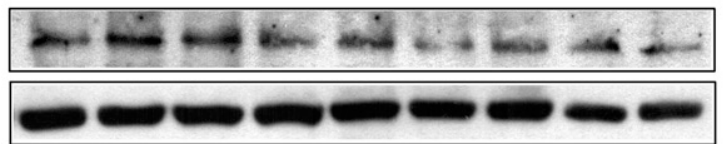

Control
19(R)-HETE
19(S)-HETE

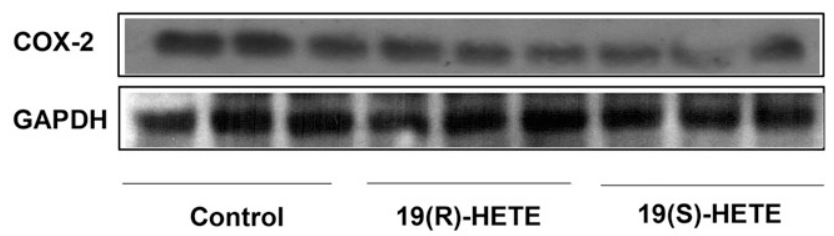

Fig. 8. Effect of 19(R)-HETE and 19(S)-HETE on protein expression level of 5-LOX, 12-LOX, 15-LOX, and COX-2 in RL-14 and H9c2 cells. RL-14 and H9c2 cells were treated for 24 hours with $20 \mu \mathrm{M}$ 19(R)-HETE or 19(S)-HETE. 5-LOX, 12-LOX, 15-LOX (A) and COX-2 (B) protein expression level were determined using Western blot analysis. Protein levels were detected using the enhanced chemiluminescence method. The intensity of the protein band was normalized to the signals obtained for $\beta$-actin or GAPDH protein and quantified using ImageJ. The results are presented as the mean and S.E.M. on the basis of at least three individual experiments. Data were analyzed using one-way ANOVA followed by Student-Newman-Keuls as post-hoc test. $* P<0.05$ significantly different from control group.

were efficient in significantly returning hypertrophic markers to almost control levels. These results provide substantial evidence that both $R$ and $S$ enantiomers of 19-HETE protect against Ang II-induced cellular hypertrophy (Fig. 9B).

Effect of 19(R)-HETE and 19(S)-HETE on Ang II-Mediated Increase of LOXs, COX-2, and Proinflammatory Cytokines at mRNA Level. To investigate whether 19(R)-HETE and 19(S)-HETE have the capacity to prevent Ang II-mediated induction of LOXs, COX-2, and proinflammatory cytokines, mRNA expression of these markers was determined using real-time PCR. The results showed that treatment of RL-14 cells with $10 \mu \mathrm{M}$ Ang II for 24 hours significantly increased the mRNA expression level of 5-LOX, 12-LOX, 15-LOX, and COX-2 by approximately $93 \%, 60 \%, 100 \%$, and $114 \%$, respectively, compared with control group (Fig. 10, A and $\mathrm{B}$ ). Interestingly, $R$ - and 


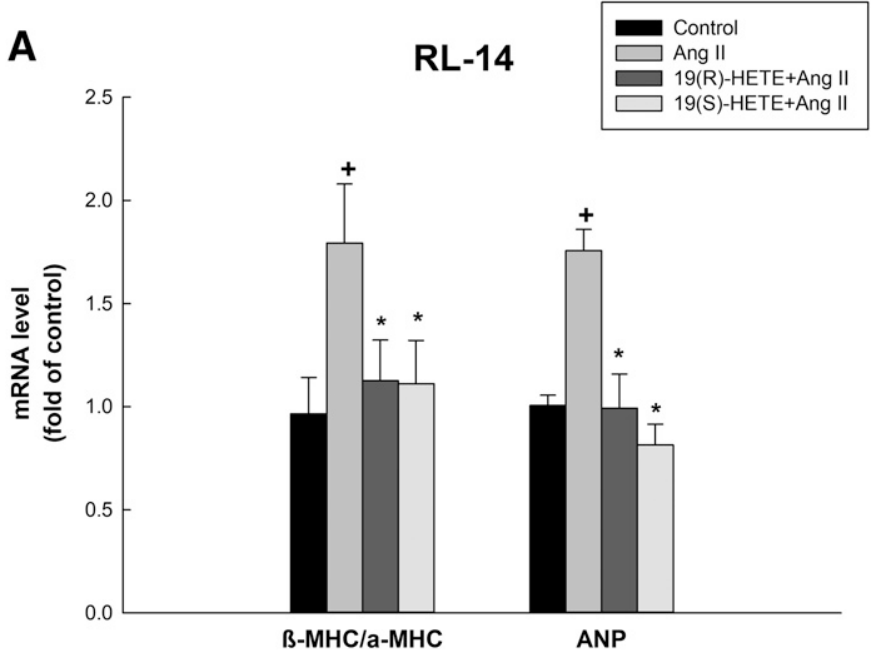

B

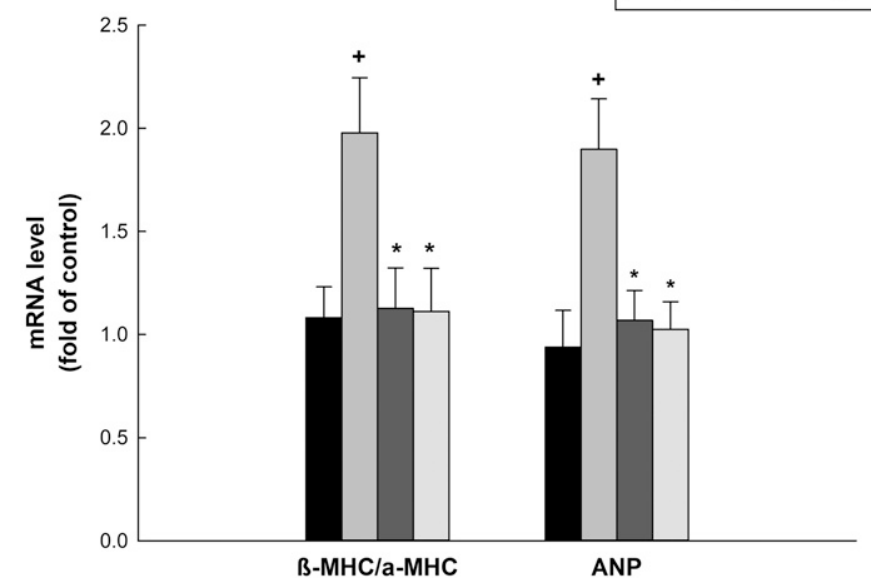

Fig. 9. Effect of 19(R)-HETE and 19(S)-HETE on Ang II-mediated induction of hypertrophic markers in RL-14 and H9c2 cells. RL-14 (A) and H9c2 (B) cells were treated for 24 hours with vehicle or $10 \mu \mathrm{M}$ Ang II in the absence and presence of $20 \mu \mathrm{M} 19(R)$-HETE or 19(S)-HETE. Total RNA was isolated using TRIzol, the mRNA expression levels of $\beta$-MHC/ $\alpha$-MHC and ANP were assessed using real time-PCR, and their levels were normalized to $\beta$-actin housekeeping gene. The results are presented as the mean and S.E.M. on the basis of at least three individual experiments. Data were analyzed using one-way ANOVA followed by StudentNewman-Keuls as post-hoc test. ${ }^{+} P<0.05$ significantly different from control group. ${ }^{*} P<0.05$ significantly different from Ang II-treated group.

$S$-enantiomers of 19-HETE significantly prevented the Ang II-mediated induction of mRNA expression of these enzymes to nearly control levels, whereas the mRNA expression of 15-LOX was decreased to control level solely by the $S$ enantiomer (Fig. 10, A and B). Furthermore, $\mathrm{H} 9 \mathrm{c} 2$ cells were used to confirm the results obtained from RL-14 cells and the data showed that Ang II significantly increased the mRNA expression level of 5-LOX, 12-LOX, 15-LOX, and COX-2 by approximately $150 \%, 83 \%, 100 \%$, and $81 \%$, respectively, compared with control group (Fig. 10, A and B). On the other hand, treatment of H9c2 with $19(R)$-HETE and $19(S)$-HETE completely prevented the Ang II-mediated induction of LOXs and COX-2 at the mRNA expression level.
Treatment of RL-14 cells with $10 \mu \mathrm{M}$ Ang II for 24 hours significantly increased the gene expression of both IL- 6 and IL- 8 by approximately $98 \%$ and $76 \%$, respectively, compared with control group (Fig. 10C). On the other hand, $R$ and $S$ enantiomers reduced the Ang II-mediated induction of these two genes. 19(R)-HETE was able to partially decrease the mRNA expression level of IL- 6 and IL- 8 by approximately $47 \%$ and $39 \%$, respectively, compared with Ang II-treated group. Interestingly, 19(S)-HETE reduced mRNA expression of IL-6 and IL-8 to nearly control level. To further confirm our results, $\mathrm{H} 9 \mathrm{c} 2$ cells were used to represent another species. The results show that both enantiomers were able to decrease the Ang II-mediated induction of IL-6 and IL-8 gene expression to almost control levels (Fig. 10C).

\section{Discussion}

Recent studies provide strong evidence that P450 enzymes and their AA metabolites play differential roles in most cardiac diseases; some of these metabolites are cadiotoxic, others showed cardioprotective effects (Westphal et al., 2015; Zu et al., 2016). One group of AA metabolites that have not been fully studied with respect to cardiac hypertrophy is subterminal HETEs, specifically 16-, 17-, 18-, and 19-HETE. Each member of subterminal HETEs has two enantiomers: $R$ - and $S$-enantiomers. Various enantiomers of a chiral drug may differ in such properties such as drug absorption, metabolism, P450 induction, or inhibition and excretion (Campo et al., 2009). Among the subterminal HETEs, 19-HETE, is considered the main subterminal HETEs in the heart and has been given the keenest attention (El-Sherbeni and El-Kadi, 2014). Therefore, in the present study, we examined the effects of $R$ and $S$ enantiomers of 19-HETE on cardiac P450 enzymes and their associated AA metabolites (subterminal/terminal HETEs, midchain HETEs, and EETs). Since there was no change in the level of AA metabolites except for midchain HETEs, we characterized the three different pathways involved in the formation of midchain HETEs and tested whether $R$ - or $S$-enantiomers have cardioprotective effect against Ang II-induced cellular hypertrophy.

To determine the nontoxic concentration of both enantiomers that would be used in the present study, we examined the effect of increasing concentrations of both enantiomers on cell viability. On the basis of MTT assay results as well as our previously published study, a concentration of $20 \mu \mathrm{M} R$ - and $S$-enantiomers was selected for further investigation (Elkhatali et al., 2015). The novel finding of the present study is that both $19(R)$-HETE and 19(S)-HETE significantly decreased the metabolite formation rate of most midchain HETEs, whereas the level of 5-HETE was selectively decreased by the $S$-enantiomer. Several pieces of evidence strongly suggest the role of midchain HETEs in the pathogenesis of cardiac hypertrophy. It has been reported that 15-HETE is able to increase the sensitivity of isoproterenol-induced $\beta$-adrenergic response in rat neonatal cardiomyocytes. In addition, 5-, 12-, and 15-HETE were able to induce cellular hypertrophy in human ventricular cardiomyocyte RL-14 cells through mitogen-activated protein kinase (MAPK)- and nuclear factor $\kappa \mathrm{B}$-dependent pathways (Zhang et al., 2014; Maayah and El-Kadi, 2016a).

The concentration of AA used in the present study was chosen because the intracellular concentration of unesterified AA is widely believed to be in the micromolar range, on the basis of reports in which the total concentration of unesterified AA was determined in different tissues. For example, AA concentration has been reported as $13-44 \mu \mathrm{M}$ in umbilical cord and intervillous space (Benassayag et al., 1997), 18.9 $\mu \mathrm{g} / \mathrm{g}$ (approximately equivalent to $60 \mu \mathrm{M}$ ) in skin (Hammarström et al., 1975), and $75 \mu \mathrm{g} / \mathrm{g}$ (approximately equivalent to $250 \mu \mathrm{M}$ ) in liver (Edpuganti and Mehvar, 2014). Therefore, 50-100 $\mu \mathrm{M}$ AA was used in 
A
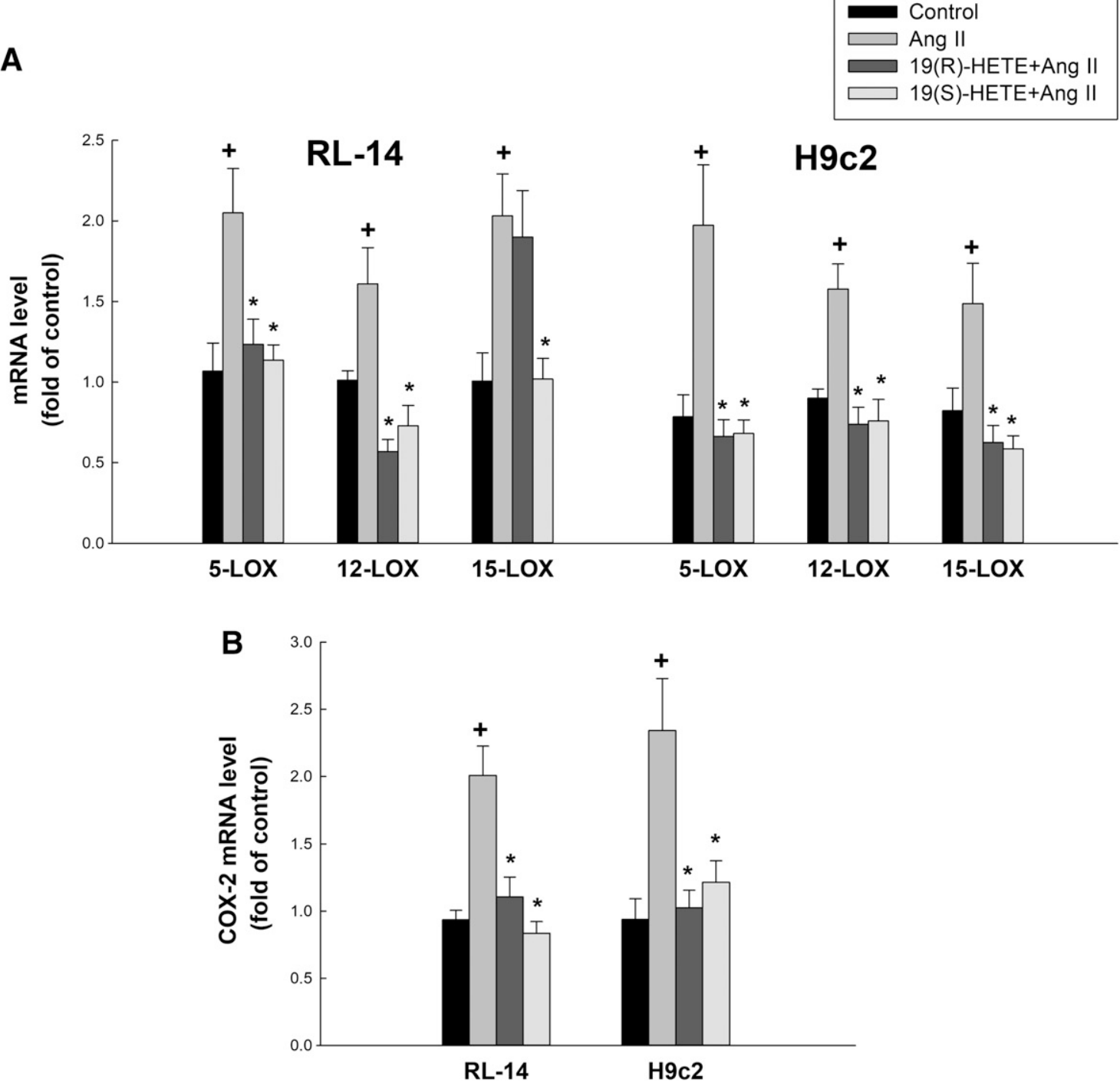

C

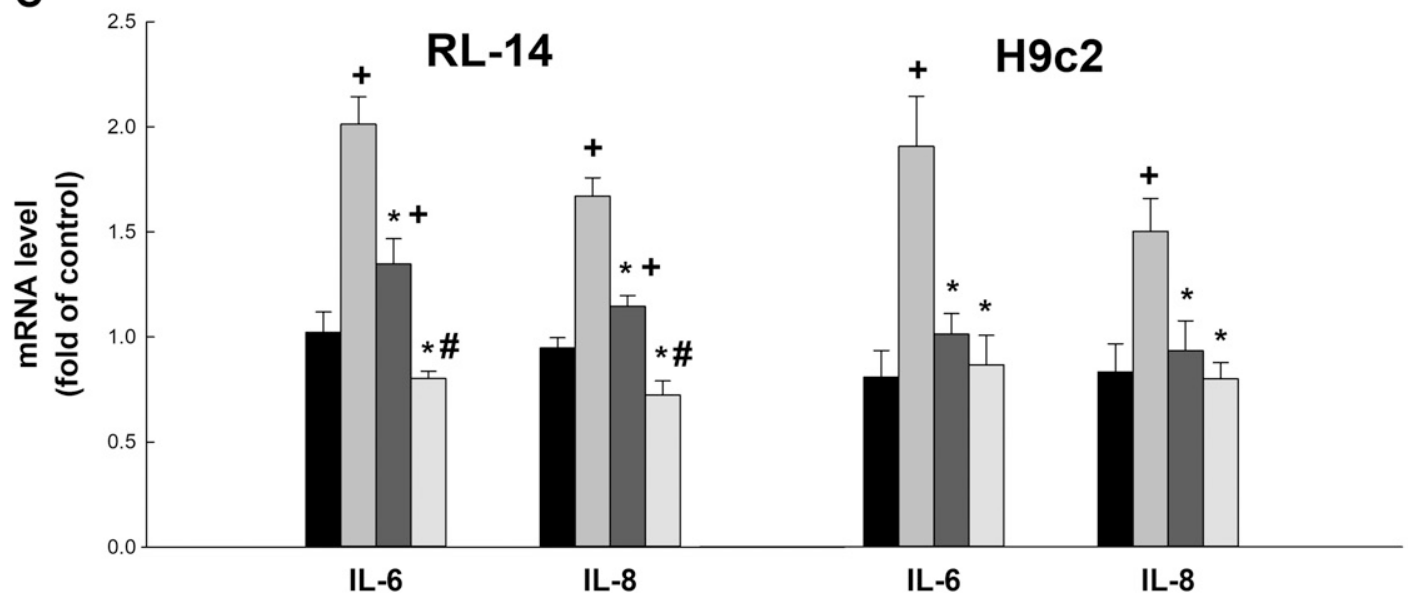

Fig. 10. Effect of 19(R)-HETE and 19(S)-HETE on Ang II-mediated induction of LOXs, COX-2, and proinflammatory cytokine mRNA expression in RL-14 and H9c2 cells. RL-14 and H9c2 cells were treated for 24 hours with vehicle or $10 \mu \mathrm{M}$ Ang II in the absence and presence of $20 \mu \mathrm{M}$ 19(R)-HETE or 19(S)-HETE. Total RNA was isolated using TRIzol, the mRNA expression levels of LOXs (A), COX-2 (B), and interleukins (C) were assessed using real time-PCR, and their levels were normalized to $\beta$-actin housekeeping gene. The results are presented as the mean and S.E.M. on the basis of at least three individual experiments. Data were analyzed using one-way ANOVA followed by Student-Newman-Keuls as post-hoc test. ${ }^{+} P<0.05$ significantly different from control group. ${ }^{*} P<0.05$ significantly different from Ang II-treated group. ${ }^{\#} P<$ 0.05 significantly different from $19(R)$-HETE-treated group. 
several published studies that used AA and P450 incubation experiments (Xu et al., 2004; Imaoka et al., 2005).

Inhibiting the formation of 5-HETE metabolite significantly protected against Ang II-induced cardiac hypertrophy in mice suggesting that inhibiting its formation could be a novel strategy to treat cardiac hypertrophy (Revermann et al., 2011). The results of the present study highlight the preferential effect of the $S$-enantiomer of 19-HETE in decreasing the formation of 5-HETE.

To determine the pathway that is involved in the decrease in the level of midchain HETEs, three pathways were examined in this study. In the heart, midchain HETEs are formed through three different metabolic pathways (Konkel and Schunck, 2011). The first metabolic pathway is P450 enzymes, particularly CYP1B1. CYP1B1 is constitutively expressed in the cardiac tissue, and several reports have confirmed the association between this enzyme and cardiovascular disease states (Zordoky and El-Kadi, 2008; Chung et al., 2012). For example, blood pressure elevation induced by Ang II was reduced in Cyp1b1-null mice compared with wildtype mice (Jennings et al., 2010). Protein expression and catalytic activity of CYP1B1 were significantly increased in three different experimental models of cardiac hypertrophy, including pressure overload-induced, isoproterenol-induced, and Ang II-induced cardiac hypertrophy (Jennings et al., 2010; El-Sherbeni and El-Kadi, 2014; Maayah et al., 2017). Recently, we demonstrated that 2-methoxyestradiol, a selective CYP1B1 inhibitor, protected against pressure overload-induced left ventricular hypertrophy in rats (Maayah et al., 2018).

One of the important findings of the present study is that both enantiomers of 19-HETE significantly inhibited CYP1B1 catalytic activity in both cell lines (RL-14 and H9c2) without altering its mRNA or protein levels, suggesting direct inhibition of its catalytic activity ( $\mathrm{Li}$ et al., 2017). Interestingly, 19(S)-HETE selectively induced the mRNA and protein expression levels of CYP4F2 and CYP4F11, which have been reported to be involved in the degradation of midchain HETEs (Maayah and El-Kadi, 2016b). It is important to mention that CYP4F2 and CYP4F11 are involved in 20-HETE as well as 19-HETE formation in human. Therefore, our data suggest that 19(S)-HETE may inhibit the catalytic activity of 20-HETE-forming enzymes (CYP4F2 and CYP4F11), which may explain the unchanged level of 20-HETE. These data were substantiated by the fact that 19-HETE is a well known endogenous antagonist of 20-HETE which may explain the cardioprotective effect of 19(S)-HETE (El-Sherbeni and El-Kadi, 2016). On the other hand, both enantiomers did not affect CYP2B6, CYP2C8, or CYP2J2 at gene or protein expression levels. This was further supported by the unchanged metabolite formation rate of EETs, the major products of these enzymes (Zhou et al., 2018).

The other two pathways that are involved in the formation of midchain HETEs are LOX and COX-2 enzymes. 5-LOX, 12-LOX, and 15-LOX enzymes metabolize AA to produce 5-, 12-, and 15-HETE, respectively (Porro et al., 2014; Radmark et al., 2015; Mao et al., 2016). In addition, it has been reported that minor quantities of midchain HETEs are produced by COX-2 enzyme (Bai and Zhu, 2008). Several studies have highlighted the role of LOXs in the pathogenesis of cardiovascular diseases including stroke, atherosclerosis, and myocardial infarction (Pergola and Werz, 2010). For instance, products of the LOXs pathway are involved in cell proliferation regulation and cell survival. Cardiovascular events such as coronary artery vasoconstriction leading to compromised ventricular contraction, decrease in blood flow to coronary arteries, and depressed cardiac output have also been associated with different metabolites of these enzymes (Vila, 2004; Werz and Steinhilber, 2006). 15-LOX was involved in the pathogenesis of Ang II-induced cardiac hypertrophy in mice. Treatment with the15-LOX inhibitor baicalein showed cardioprotective effect through inhibition of 15-LOX (Wang et al., 2015). Furthermore, COX-2 enzyme activation leads to cardiac cell death, decrease in myocardial function, and consequent heart failure (Lamon et al., 2010).

In the present study, $S$-enantiomer of 19-HETE selectively decreased the protein expression level of 15-LOX in human cardiomyocytes, whereas 5-LOX, 12-LOX, and COX-2 protein expression was decreased by both enantiomers in RL-14x and H9c2 cells. To the best of our knowledge, this is the first study to reveal how 19(R)-HETE and 19(S)-HETE modulate P450, LOXs, and COX-2 enzymes in cardiac cells. The ability of 19(S)-HETE to inhibit CYP1B1, LOXs, and COX-2 pathways and their associated proinflammatory metabolites is of significant benefit in designing novel therapeutic modalities for cardiac hypertrophy.

In the present study, both enantiomers of 19-HETE protected against Ang II-induced cellular hypertrophy as evidenced by a substantial decrease in $\beta$-MHC/ $\alpha$-MHC ratio and ANP mRNA expression, in RL-14 and H9c2 cells. The protective effect of each enantiomer of 19-HETE against cellular hypertrophy has never been reported before; however, we have previously demonstrated that a racemic mixture of 19-HETE protected against Ang II-induced cardiac hypertrophy (Elkhatali et al., 2015).

In the present study, both enantiomers of 19-HETE inhibited Ang II-mediated increase of both IL- 6 and IL- 8 compared with the control group, with preferential effect of the $S$-enantiomer. Interleukins are group of cytokines that have a central role in pathogenesis of cardiac hypertrophy. IL-6 and IL-8 are considered the main hypertrophic cytokines that mediate their effects through Janus kinase/signal transducers and activators of transcription, MAPK, and PI3K pathways (Rohini et al., 2010). IL-8 was significantly higher in the thoracic aorta of spontaneously hypertensive rats compared with normotensive rats. This finding suggests that IL-8 plays an important role in the pathogenesis of hypertension and cardiac hypertrophy (Apostolakis et al., 2009). Treatment of hypertensive rats with reparixin, an IL-8 receptor inhibitor, caused a significant reduction in blood pressure (Martynowicz et al., 2014).

In summary, our data demonstrate that both enantiomers of 19-HETE protected against Ang II-induced cardiac hypertrophy by decreasing the level of midchain HETEs, inhibiting the catalytic activity of CYP1B1, decreasing the protein expression level of LOX and COX-2 enzymes, and decreasing the mRNA expression level of proinflammatory markers IL-6 and IL-8. It is noteworthy that the $S$-enantiomer demonstrated more protection than the $R$-enantiomer, reflected in its ability to decrease the level of 5-HETE, decrease the protein expression of 15-LOX, increase the protein expression level of CYP4F2 and CYP4F11, and exert preferential effect on IL- 6 and IL-8 compared with the $R$-enantiomer.

\section{Authorship Contributions \\ Participated in research design: Shoieb, El-Kadi. \\ Conducted experiments: Shoieb. \\ Performed data analysis: Shoieb, El-Kadi. \\ Wrote or contributed to the writing of the manuscript: Shoieb, El-Kadi.}

\section{References}

Apostolakis S, Vogiatzi K, Amanatidou V, and Spandidos DA (2009) Interleukin 8 and cardiovascular disease. Cardiovasc Res 84:353-360.

Bai HW and Zhu BT (2008) Strong activation of cyclooxygenase I and II catalytic activity by dietary bioflavonoids. J Lipid Res 49:2557-2570

Benassayag C, Mignot TM, Haourigui M, Civel C, Hassid J, Carbonne B, Nunez EA, and Ferre F (1997) High polyunsaturated fatty acid, thromboxane A2, and alpha-fetoprotein concentrations at the human feto-maternal interface. J Lipid Res 38:276-286.

Benjamin EJ, Blaha MJ, Chiuve SE, Cushman M, Das SR, Deo R, De Ferranti SD, Floyd J, Fornage M, Gillespie C, et al. (2017) Heart disease and stroke statistics-2017 update: a report from the American Heart Association [published correction appears in Circulation (2017) 135: e646; 136:e196]. Circulation 135:e146-e603

Bernardo BC, Weeks KL, Pretorius L, and McMullen JR (2010) Molecular distinction between physiological and pathological cardiac hypertrophy: experimental findings and therapeutic strategies. Pharmacol Ther 128:191-227. 
Brown DW, Giles WH, and Croft JB (2000) Left ventricular hypertrophy as a predictor of coronary heart disease mortality and the effect of hypertension. Am Heart J 140:848-856.

Campo VL, Bernardes LS, and Carvalho I (2009) Stereoselectivity in drug metabolism: molecular mechanisms and analytical methods. Curr Drug Metab 10:188-205.

Chandrasekharan JA, Marginean A, and Sharma-Walia N (2016) An insight into the role of arachidonic acid derived lipid mediators in virus associated pathogenesis and malignancies. Prostaglandins Other Lipid Mediat 126:46-54.

Cheng J, Ou J-S, Singh H, Falck JR, Narsimhaswamy D, Pritchard KA, Jr, and Schwartzman ML (2008) 20-hydroxyeicosatetraenoic acid causes endothelial dysfunction via eNOS uncoupling. Am J Physiol Heart Circ Physiol 294:H1018-H1026.

Chung E, Heimiller J, and Leinwand LA (2012) Distinct cardiac transcriptional profiles defining pregnancy and exercise. PLoS One 7:e42297.

Dhanasekaran A, Al-Saghir R, Lopez B, Zhu D, Gutterman DD, Jacobs ER, and Medhora M (2006) Protective effects of epoxyeicosatrienoic acids on human endothelial cells from the pulmonary and coronary vasculature. Am J Physiol Heart Circ Physiol 291:H517-H531.

Edpuganti V and Mehvar R (2014) UHPLC-MS/MS analysis of arachidonic acid and 10 of its major cytochrome $\mathrm{P} 450$ metabolites as free acids in rat livers: effects of hepatic ischemia. $J$ Chromatogr B Analyt Technol Biomed Life Sci 964:153-163.

Elkhatali S, El-Sherbeni AA, Elshenawy OH, Abdelhamid G, and El-Kadi AO (2015) 19Hydroxyeicosatetraenoic acid and isoniazid protect against angiotensin II-induced cardiac hypertrophy. Toxicol Appl Pharmacol 289:550-559.

Elkhatali S, Maayah ZH, El-Sherbeni AA, Elshenawy OH, Abdelhamid G, Shoieb SM, and ElKadi AOS (2017) Inhibition of mid-chain HETEs protects against angiotensin II-induced cardiac hypertrophy. J Cardiovasc Pharmacol 70:16-24.

Elshenawy OH, Anwar-Mohamed A, and El-Kadi AO (2013) 20-Hydroxyeicosatetraenoic acid is a potential therapeutic target in cardiovascular diseases. Curr Drug Metab 14:706-719.

Elshenawy OH, Shoieb SM, Mohamed A, and El-Kadi AO (2017) Clinical implications of 20-hydroxyeicosatetraenoic acid in the kidney, liver, lung and brain: an emerging therapeutic target. Pharmaceutics 9 DOI: 10.3390/pharmaceutics 9010009.

El-Sherbeni AA and El-Kadi AO (2014) Alterations in cytochrome P450-derived arachidonic acid metabolism during pressure overload-induced cardiac hypertrophy. Biochem Pharmacol 87: 456-466.

El-Sherbeni AA and El-Kadi AOS (2016) Repurposing resveratrol and fluconazole to modulate human cytochrome P450-mediated arachidonic acid metabolism. Mol Pharm 13:1278-1288.

Hammarström S, Hamberg M, Samuelsson B, Duell EA, Stawiski M, and Voorhees JJ (1975) Increased concentrations of nonesterified arachidonic acid, 12L-hydroxy-5,8,10,14-eicosatetraenoic acid, prostaglandin E2, and prostaglandin F2alpha in epidermis of psoriasis. Proc Nat Acad Sci USA 72:5130-5134.

Heart and Stroke Foundation (2016) 2016 Report on the Health of Canadians. Ottawa, Canada.

Imaoka S, Hashizume T, and Funae Y (2005) Localization of rat cytochrome P450 in various tissues and comparison of arachidonic acid metabolism by rat P450 with that by human $\mathrm{P} 450$ orthologs. Drug Metab Pharmacokinet 20:478-484.

Jennings BL, Sahan-Firat S, Estes AM, Das K, Farjana N, Fang XR, Gonzalez FJ, and Malik KU (2010) Cytochrome P450 1B1 contributes to angiotensin II-induced hypertension and associated pathophysiology. Hypertension 56:667-674

Konkel A and Schunck WH (2011) Role of cytochrome P450 enzymes in the bioactivation of polyunsaturated fatty acids. Biochim Biophys Acta 1814:210-222.

Lamon BD, Upmacis RK, Deeb RS, Koyuncu H, and Hajjar DP (2010) Inducible nitric oxide synthase gene deletion exaggerates MAPK-mediated cyclooxygenase-2 induction by in flammatory stimuli. Am J Physiol Heart Circ Physiol 299:H613-H623.

Li F, Zhu W, and Gonzalez FJ (2017) Potential role of CYP1B1 in the development and treatment of metabolic diseases. Pharmacol Ther 178:18-30.

Lorenzen A and Kennedy SW (1993) A fluorescence-based protein assay for use with a microplate reader. Anal Biochem 214:346-348.

Lowry OH, Rosebrough NJ, Farr AL, and Randall RJ (1951) Protein measurement with the Folin phenol reagent. J Biol Chem 193:265-275.

Maayah ZH, Althurwi HN, El-Sherbeni AA, Abdelhamid G, Siraki AG, and El-Kadi AO (2017) The role of cytochrome P450 1B1 and its associated mid-chain hydroxyeicosatetraenoic acid metabolites in the development of cardiac hypertrophy induced by isoproterenol. Mol Cell Biochem 429:151-165.
Maayah ZH and El-Kadi AO (2016a) 5-, 12- and 15-Hydroxyeicosatetraenoic acids induce cellular hypertrophy in the human ventricular cardiomyocyte, RL-14 cell line, through MAPK- and NF-кB-dependent mechanism. Arch Toxicol 90:359-373.

Maayah ZH and El-Kadi AO (2016b) The role of mid-chain hydroxyeicosatetraenoic acids in the pathogenesis of hypertension and cardiac hypertrophy. Arch Toxicol 90:119-136.

Maayah ZH, Levasseur J, Siva Piragasam R, Abdelhamid G, Dyck JRB, Fahlman RP, Siraki AG, and El-Kadi AOS (2018) 2-Methoxyestradiol protects against pressure overload-induced left ventricular hypertrophy. Sci Rep 8:2780.

Mao JT, Smoake J, Park HK, Lu QY, and Xue B (2016) Grape seed procyanidin extract mediates antineoplastic effects against lung cancer via modulations of prostacyclin and 15-HETE eicosanoid pathways. Cancer Prev Res (Phila) 9:925-932.

Martynowicz H, Janus A, Nowacki D, and Mazur G (2014) The role of chemokines in hypertension. Adv Clin Exp Med 23:319-325.

Mosli HH, Esmat A, Atawia RT, Shoieb SM, Mosli H a, and Abdel-Naim AB (2015) Metformin Attenuates Testosterone-Induced Prostatic Hyperplasia in Rats: A Pharmacological Perspective. Sci Rep 5:15639, Nature Publishing Group.

Pergola C and Werz O (2010) 5-Lipoxygenase inhibitors: a review of recent developments and patents. Expert Opin Ther Pat 20:355-375.

Porro B, Songia P, Squellerio I, Tremoli E, and Cavalca V (2014) Analysis, physiological and clinical significance of 12-HETE: a neglected platelet-derived 12-lipoxygenase product. $J$ Chromatogr B Analyt Technol Biomed Life Sci 964:26-40.

Rådmark O, Werz O, Steinhilber D, and Samuelsson B (2015) 5-Lipoxygenase, a key enzyme for leukotriene biosynthesis in health and disease. Biochim Biophys Acta 1851:331-339.

Revermann M, Mieth A, Popescu L, Paulke A, Wurglics M, Pellowska M, Fischer AS, Steri R, Maier TJ, Schermuly RT, et al. (2011) A pirinixic acid derivative (LP105) inhibits murine 5 -lipoxygenase activity and attenuates vascular remodelling in a murine model of aortic aneurysm. Br J Pharmacol 163:1721-1732.

Rohini A, Agrawal N, Koyani CN, and Singh R (2010) Molecular targets and regulators of cardiac hypertrophy. Pharmacol Res 61:269-280.

Roman RJ (2002) P-450 metabolites of arachidonic acid in the control of cardiovascular function. Physiol Rev 82:131-185.

Vila L (2004) Cyclooxygenase and 5-lipoxygenase pathways in the vessel wall: role in atherosclerosis. Med Res Rev 24:399-424.

Wang A-W, Song L, Miao J, Wang H-X, Tian C, Jiang X, Han Q-Y, Yu L, Liu Y, Du J, et al. (2015) Baicalein attenuates angiotensin II-induced cardiac remodeling via inhibition of AKT/mTOR, $\mathrm{ERK} 1 / 2$, NF-кB, and calcineurin signaling pathways in mice. Am J Hypertens 28:518-526.

Werz O and Steinhilber D (2006) Therapeutic options for 5-lipoxygenase inhibitors. Pharmacol Ther 112:701-718.

Westphal C, Konkel A, and Schunck WH (2015) Cytochrome p450 enzymes in the bioactivation of polyunsaturated fatty acids and their role in cardiovascular disease. Adv Exp Med Biol 851: 151-187.

Xu F, Falck JR, Ortiz de Montellano PR, and Kroetz DL (2004) Catalytic activity and isoformspecific inhibition of rat cytochrome p450 4F enzymes. I Pharmacol Exp Ther 308:887-895.

Zhang L, Li Y, Chen M, Su X, Yi D, Lu P, and Zhu D (2014) 15-LO/15-HETE mediated vascular adventitia fibrosis via p38 MAPK-dependent TGF- $\beta$. J Cell Physiol 229:245-257.

Zhou C, Huang J, Li Q, Zhan C, Xu X, Zhang X, Ai D, Zhu Y, Wen Z, and Wang DW (2018) CYP2J2-derived EETs attenuated ethanol-induced myocardial dysfunction through inducing autophagy and reducing apoptosis. Free Radic Biol Med 117:168-179.

Zordoky BN and El-Kadi AO (2008) Modulation of cardiac and hepatic cytochrome P450 enzymes during heart failure. Curr Drug Metab 9:122-128.

Zu L, Guo G, Zhou B, and Gao W (2016) Relationship between metabolites of arachidonic acid and prognosis in patients with acute coronary syndrome. Thromb Res 144:192-201.

Address correspondence to: Dr. Ayman O. S. El-Kadi, Faculty of Pharmacy and Pharmaceutical Sciences, 2142J Katz Group-Rexall Centre for Pharmacy and Health Research, University of Alberta, Edmonton, AB, Canada T6G 2E1. E-mail: aelkadi@ualberta.ca 